\title{
2 Areal und Struktur: Grundlagen und Forschungsüberblick
}

\subsection{Zielsetzung des Kapitels}

Das folgende Kapitel fasst die bisherigen Erkenntnisse der Forschungsliteratur aus Dialektologie und Variationslinguistik zur strukturellen und geographischen Gliederung der deutschen dialektalen Kasussysteme zusammen. Der Schwerpunkt der Beschreibung liegt dabei - soweit möglich - auf dem Gebiet des Oberdeutschen in Baden-Württemberg und Bayerisch-Schwaben, das für die Korpusanalyse relevant ist.

Insbesondere im Hinblick auf mögliche morphosyntaktische Einflüsse auf das Kasusdiasystem bietet die dialektologische Forschung bislang noch relativ wenige Einblicke. Zwar gibt es einige Arbeiten, die sich bereits mit diesen Einflüssen auseinandergesetzt haben und durchaus relevante Einblicke gewähren. Diese betrachten jedoch jeweils nur einen Ausschnitt des Kasusdiasystems, beispielsweise eine bestimmte Wortart oder spezielle Kategorien und Kontexte. ${ }^{2}$ An dieser Stelle werde ich daher auch Erkenntnisse aus der Sprachtypologie und der Forschung zur deutschen Standardsprache einbeziehen, die den hier bisher recht knappen Forschungsstand der Dialektologie gewinnbringend erweitern können.

Im Teilkapitel zur strukturellen Gliederung des Kasusdiasystems wird zunächst die in der Arbeit genutzte Terminologie eingeführt. Basierend auf einem kurzen Überblick über seine diachrone Entwicklung wird das (ober)deutsche Kasusdiasystem dann auf Grundlage kasustypologischer Kriterien klassifiziert. Neben der inhaltlichen Beschreibung der bisherigen Erkenntnisse zu Struktur und Geographie der oberdeutschen Kasussysteme hat dieses Kapitel auch die Funktion - vorbereitend auf die folgende empirische Untersuchung -, Theorie und Methodik des Forschungsfelds der dialektologischen bzw. dialektgeographischen Kasusmorphologie zu skizzieren.

2 Beispielsweise Dal Negro (2004) zum Paradigma alemannischer Definitartikel, Fleischer (2006) zum Kasus indirekter Objekte in Relativsätzen, Rabanus (2008) zu Pronominalparadigmen im Minimalsatz, Alber/Rabanus (2011) zu germanischen, explizit auch zu hochdeutschen Personalpronomen, Rauth (2016) zur Interaktion von Kasusdistinktion und Abfolge von direktem und indirektem Objekt, Baechler (2017) zur Komplexität in der Nominalflexion und Perrig (2018) zu Paradigmen alemannischer Artikel und Adjektive. 


\subsection{Struktur des Kasusdiasystems}

\subsubsection{Zur Multidimensionalität des Kasusbegriffs: Terminologische Grundlagen}

As in all areas of grammar, the terminology surrounding case phenomena is often not straightforward: Linguists with different backgrounds use the same terms for somewhat or radically different concepts, or they use different terms for very similar or identical concepts.

(Haspelmath 2009: 505)

Die Kategorie Kasus befindet sich an der Schnittstelle verschiedener linguistischer Ebenen - allen voran der Morphologie, aber auch der Syntax, der Semantik und der Morphologie. Diese Schnittstellenposition spiegelt sich auch in einer Multidimensionalität des Kasusbegriffs wider, was mitunter zu terminologischer Uneinheitlichkeit in der vorhandenen Forschungsliteratur führt. Diese Uneinheitlichkeit wird zudem durch die verschiedenen Forschungstraditionen verstärkt, die sich aus unterschiedlichen Perspektiven und auf Grundlage verschiedener Sprachsysteme mit Kasus beschäftigen (vgl. dazu auch die terminologische Übersicht in Haspelmath 2009). Im Folgenden werden daher zunächst die kasusspezifische Terminologie, die in dieser Arbeit genutzt wird, und die theoretischen Ausgangspunkte der Untersuchung definiert. Eine zusammenfassende Illustration dieser Definition findet sich dann in Abb. 2.

Syntax und Semantik Morphologie Phonologie

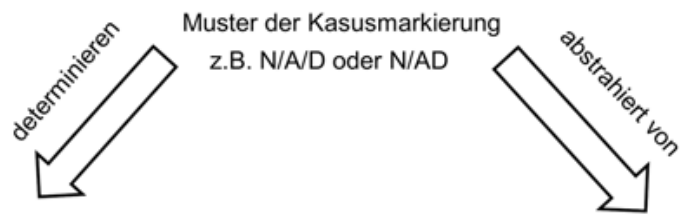

abstrakte Kasus

z.B. Nominativ

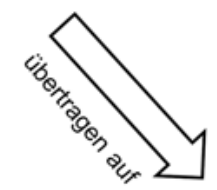

kasustragende Wortarten

z.B. Personalpronomen morphophonologische Oberflächenstruktur z.B. ich, mich

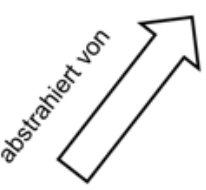

Typen der Kasusmarkierung z.B. Suppletion

Abb. 2: Ebenen der Kategorie Kasus und terminologische Grundlagen. 
Der Begriff Kasus bezeichnet zunächst eine abstrakte Eigenschaft von Nominalphrasen. Diese lässt sich im Grunde nur über ihre Funktion, ihre Form oder über eine Kombination aus diesen funktionalen und formalen Aspekten definieren. Die funktionale Definition erfolgt dabei auf syntaktischer und semantischer und die formale Definition auf morphophonologischer Ebene. Die Kasusmorphologie selbst, die die formale und funktionale Definition kombiniert, lässt sich dabei auf einer Ebene dazwischen ansiedeln. Sie weist sowohl Schnittstellen zur funktionalen als auch zur formalen Ebene auf. Blake (2001: 1) definiert Kasus auf funktionaler Ebene als Eigenschaft abhängiger Nomen (beziehungsweise Nominalphrasen), ihre Beziehung zum jeweiligen Kopf zu markieren. Diese Eigenschaft (bei Dürscheid 1999: 2 etwa als „Kasuskategorie“ bezeichnet), wird folglich von einem Verb oder einer Präposition regiert und damit „von außen“ auf die Nominalphrase, beziehungsweise auf deren Komponenten, übertragen.

In dieser Arbeit wird diese Ebene der Kategorie Kasus als abstrakter Kasus bezeichnet, der formal nicht unbedingt durch eine konkrete Form oder einen konkreten Marker ausgedrückt wird (vgl. etwa Blake 2001: 57). Abstrakter Kasus hat verschiedene Ausprägungen (z. B. die Kasus Nominativ, Akkusativ und Dativ), die sowohl funktional als auch formal determiniert werden können. Funktional können sie über die grammatischen Relationen, die sie ausdrücken, voneinander abgegrenzt werden, formal über unterschiedlichen Formen, d. h. ihre Distinktion im Paradigma (bzw. Syntagma). Angelehnt an die klassische linguistische Tradition, die auf Systembeschreibungen des Lateinischen und Altgriechischen beruht, werden dabei diejenigen abstrakten Kasus angesetzt, die mindestens an einer Stelle im Kasussystem, also in einer Kategorie oder bei einer kasustragenden Wortart, formal distinkt realisiert werden (vgl. Blake 2001: 5 und Comrie 2010: 41). Damit unterscheidet sich die Definition des abstrakten Kasus hier grundlegend von der der generativen Tradition (vgl. etwa Chomsky 2010). Während die Kategorie der abstrakten Kasus dort vollkommen unabhängig vom formalen Ausdruck auf jede Nominalphrase übertragen wird, auch z. B. in Systemen, die keine oder kaum Kasusdistinktionen markieren, werden die einzelnen Ausprägungen des abstrakten Kasus hier aufgrund der formalen paradigmatischen Differenzierung an einer Stelle im System definiert. Damit ist die hier genutzte Definition des abstrakten Kasus auch an die morphophonologische Oberflächenstruktur und damit auch an die formale Ebene der Kategorie Kasus geknüpft.

Methodisch kann die Ebene des abstrakten Kasus hier damit als eine Art „Maximalhypothese“ gewertet werden. Abstrakter Kasus wird zunächst auf Basis der bisherigen Forschungsliteratur für bestimmte Wortarten angenommen. Finden sich innerhalb der Analyse keine Belege für eine formal distinkte Kasusmarkierung 
in dieser Wortart, kann daraus geschlossen werden, dass diese Wortart keinen abstrakten Kasus trägt.

Wie oben bereits erwähnt, besteht die Funktion von Kasus grundlegend darin, die grammatischen Relationen auszudrücken, die die verschiedenen Nominalphrasen zueinander und zu dem Verb oder der Präposition einnehmen, das oder die sie regiert (vgl. Blake 2001: 1) und damit grundlegend die Argumentstruktur zu markieren. Diese grammatischen Relationen können wiederum - je nach Forschungstradition oder Eigenschaft des $\mathrm{zu}$ beschreibenden grammatischen Systems - als syntaktische Funktionen oder als semantische Rollen oder mithilfe einer Kombination dieser beiden Ansätze determiniert werden. Damit bildet die Funktion der Kategorie Kasus das Bindeglied des abstrakten Kasus zu den Ebenen der Syntax und der Semantik.

Eine weitere Komponente der Kategorie bildet der sprachspezifische formale Ausdruck des abstrakten Kasus im System. Auf Ebene der Morphologie sind dafür die grundlegenden Strukturen relevant, die zur Kasusmarkierung im jeweiligen Sprachsystem genutzt werden. Zum einen zeigen sich diese Strukturen anhand der Teile der Nominalphrase, an denen der abstrakte Kasus des Nomens im jeweiligen Sprachsystem morphologisch markiert wird - d. h. anhand der Determination der kasusmarkierenden Wortarten. Zum anderen zeigen sie sich innerhalb der morphologischen Struktur eben dieser Wortarten. Sie weisen jeweils verschiedene morphologische Typen der Kasusmarkierung - wie z. B. suppletive oder affigierte Formen - auf und lassen sich entsprechend gliedern. In Bezug auf die morphologische Struktur einer Wortart werden in dieser Arbeit angelehnt an Blake (2001: 2) Kasusformen als holistische Wortformen, die Kasus markieren, definiert. ${ }^{3}$ Damit wird ein größtenteils wortbasierter Ansatz verfolgt (vgl. etwa Stewart 2016: 5).

Obwohl Kasus als abstrakte Eigenschaft innerhalb des Systems auf verschiedene Wortarten übertragen wird und den oben genannten Annahmen zufolge demnach jede Nominalphrase selbst und innerhalb der Nominalphrase verschiedene Wortarten diese Eigenschaft tragen, wird sie auf morphophonologischer Ebene keinesfalls in jeder Kategorie distinkt ausgedrückt. Der formale Ausdruck der Kasus auf der morphophonologischen Oberfläche gliedert sich durch die zugrundeliegenden morphologischen Strukturen im Kasusparadigma. Dabei bündeln sich in den Zellen des Paradigmas die durch das Sprachsystem determinierten Eigenschaften, die einen gemeinsamen formalen Ausdruck aufweisen. Das lässt sich am Beispiel von Tab. 1 illustrieren.

3 Anders als Blake (2001: 2) differenziere ich an dieser Stelle nicht zwischen Kasusformen als vollständigen kasustragenden Wortarten und Kasusmarkern als denjenigen morphologischen Elementen, die innerhalb des Wortes zur Kasusmarkierung beitragen. Eine umfassende Diskussion dieser Tatsache und der dahinterstehenden Problematik findet sich in 3.3.1. 
Tab. 1: Beispielhaftes Kasusparadigma des Personalpronomens der 1. Person im Standarddeutschen.

\begin{tabular}{lll}
\hline & Singular & Plural \\
\hline Nominativ & ich & wir \\
\hline Akkusativ & mich & uns \\
\hline Dativ & mir & uns \\
\hline Genitiv & meiner & unser \\
\hline
\end{tabular}

Tabelle 1 illustriert ein klassisches Kasusparadigma, das in Zeilen die für das Standarddeutsche definierten Kasus Nominativ, Akkusativ, Dativ und Genitiv und in Spalten die Ausprägungen der Kategorie Numerus - Singular und Plural - abbildet. Die einzelnen Zellen enthalten den formalen Ausdruck der gebündelten Eigenschaften, d. h. z. B. [Nom, SG]: ich. Methodologisch bildet die Rekonstruktion des Kasusparadigmas eines bestimmten Systems ein Instrument, um eben diese Muster in Bezug zu den Ausprägungen der abstrakten Kasus sowie teilweise zu weiteren grammatischen Kategorien, wie etwa Person, Numerus und Genus, herauszuarbeiten. Es ermöglicht die Strukturierung der im System formal markierten morphosyntaktischen Eigenschaften. Innerhalb der Abbildung werden diese Eigenschaften in Spalten und Zeilen aufgeführt und in Zellen gebündelt. Die grundlegende Aufgabe der Rekonstruktion eines Kasusparadigmas für ein bestimmtes System besteht folglich darin, diejenigen morphosyntaktischen Eigenschaften, sowie die Ausprägungen, d. h. die einzelnen Kasus, zu definieren, die für die Beschreibung dieses Systems relevant sind.

Werden diese Eigenschaften fundiert definiert, kann die Rekonstruktion eines Kasusparadigmas in der Analyse zwei Funktionen erfüllen: Zum einen die eines Beschreibungswerkzeugs - es führt die Wortformen strukturiert nach den relevanten Bündeln von morphosyntaktischen Eigenschaften auf. Zum anderen die eines Analyseinstruments - es ermöglicht die Analyse morphophonologischer Strukturen bezogen auf die Bündel morphosyntaktischer Eigenschaften. Dabei sind weniger die einzelnen tatsächlich in den Zellen enthaltenen Wortformen - also etwa ich [Nom, SG] -, sondern vielmehr - in strukturalistischer Tradition - der Vergleich verschiedener Zellen für die Analyse - also ich [NoM, SG] vs. mich [AKK, SG] - relevant. Vielmehr als die Realisierung an der morphophonologischen Oberfläche stehen hier folglich die zugrundeliegenden morphologischen Strukturen im Vordergrund.

Enthalten zwei Zellen im direkten Vergleich verschiedene Wortformen, gelten sie als distinkt; enthalten sie dieselbe Wortform, gelten sie als synkretisch. 
In dieser Arbeit wird Synkretismus, angelehnt an Baerman et al. (2010: 7) als Formengleichheit zweier Wortformen definiert, die sich in (mindestens) einer Eigenschaft - hier in Bezug auf den abstrakten Kasus, den sie markieren unterscheiden. Diese Definition wird in 3.3.4 diskutiert und begründet.

Auf Ebene der morphophonologischen Oberflächenstruktur äußert sich der formale Ausdruck in verschiedenen Mustern der Kasusmarkierung. Diese Muster bilden die systeminternen Distinktionen der einzelnen abstrakten Kasus ab, zeigen demnach, inwiefern Kasus bei bestimmten kasustragenden Wortarten und in bestimmten morphosyntaktischen Kontexten Synkretismus oder Distinktion aufweist. Das Paradigma dieser Wortarten bildet damit eine strukturelle morphologische Abstraktion von der Oberflächenstruktur, auf deren Basis die Muster der Kasusmarkierung bestimmt werden können. Abbildung 2 illustriert die verschiedenen Ebenen der Kategorie Kasus sowie deren Beziehung untereinander und führt jeweils Beispiele dazu aus dem standarddeutschen System auf.

In der Korpusanalyse, die in dieser Arbeit vorgestellt wird, bildet eben diese Abstraktion der Muster aus der morphophonologischen Oberflächenstruktur den Zugriffspunkt für die Untersuchung von Kasussystemen: Zum einen werden auf Basis der Muster die einzelnen Kasus identifiziert, die im abstrakten Kasussystem unterschieden werden. Zum anderen bilden die Muster der Kasusmarkierung in bestimmten grammatischen Kategorien eine wichtige Grundlage für die typologische Einordnung des untersuchten Kasusdiasystems. Muster, die in einem System gefunden werden, lassen sich direkt mit den Mustern eines anderen Systems vergleichen, ohne dass dabei die möglicherweise recht unterschiedliche Oberflächenstruktur der einzelnen Kasusformen berücksichtigt werden muss.

\subsubsection{Erste Beschreibung und vorläufige typologische Einordnung}

In der folgenden Beschreibung von Entwicklung und Struktur des (ober)deutschen Kasusdiasystems werden die Beschreibungsparameter und -schwerpunkte verschiedener Forschungstraditionen - der historischen germanistischen Sprachwissenschaft, der deutschen Dialektologie sowie der Sprachtypologie - herangezogen, nach Möglichkeit kombiniert und, wo erforderlich, einander gegenübergestellt.

Grundlegend ist dabei zu klären, welche Ausprägungen des abstrakten Kasus in den Systemen im Untersuchungsgebiet angesetzt werden können und wie sich diese funktional und formal differenzieren lassen. Dazu wird zunächst die historische Entwicklung des deutschen Kasusdiasystems in ihren Grundzü- 
gen skizziert und damit herausgearbeitet, welche abstrakten Kasus angesetzt werden können, welche im Verlauf der deutschen Sprachgeschichte geschwunden sind und welche Schlüsse daraus für die typologische Einordnung des (ober)deutschen Kasusdiasystems gezogen werden können.

\subsubsection{Entwicklungen im deutschen Kasussystem}

Der folgenden Beschreibung der Entwicklungen von Kasus im Sprachsystem liegt eine Abstraktion über die verschiedenen Dialekte und Sprachstufen des Deutschen zugrunde, die in einem groben Überblick ${ }^{4}$ kaum $\mathrm{zu}$ umgehen ist. Weder sind die einzelnen Sprachstufen - insbesondere bezüglich morphologischer Kategorien - derart klar voneinander abzugrenzen, noch sind die beschriebenen Entwicklungen derart kontinuierlich belegt oder gar variationslinguistisch einheitlich, wie es diese Abstraktion suggeriert. Die Skizze soll lediglich den bisherigen Erkenntnisstand über allgemeine Tendenzen und Grundzüge in der Entwicklung des deutschen Kasusdiasystems offenlegen. ${ }^{5}$

Grundlegend ist davon auszugehen, dass im deutschen Sprachsystem alle flektierbaren Wortarten, die in einer Nominalphrase auftreten, kasustragend sein können. Dieser Umstand liegt darin begründet, dass verschiedene Prinzipien zur Positionierung der Kasusmarkierung innerhalb der Nominalphrase in der deutschen Sprachgeschichte miteinander interagieren. So wird der ursprünglich wohl hauptsächlich als Flexionssuffix am Nomen auftretende Ausdruck von Kasus diachron auf weitere Teile der Nominalphrase verteilt; ein Prozess, der mit dem zunehmenden Ausbau der Nominalklammer (vgl. etwa Ronneberger-Sibold 2010a und Ronneberger-Sibold 2010b) einhergeht: Die regressiv orientierte Markierung - etwa eines nominalen Stammes durch ein Flexionssuffix (Baum-e) - schwindet seit germanischer Zeit zunehmend. Insbesondere in den frühen Stufen des Deutschen etabliert sich die Stamm- und Wurzelflexion, ein Prinzip, bei dem Wortformen durch Wechsel des Stammvokals flektieren. Die Stamm- und Wurzelflexion tritt jedoch eher beim Ausdruck anderer Kategorien, wie etwa den im deutschen Sprachsystem zunehmend profilierten Numerus, auf. Daneben findet sich in den neueren Sprachstufen zunehmend das Prinzip der progressiven Flexion - der

4 Der Fokus dieser Arbeit liegt auf einer (relativ) synchronen Beschreibung des Kasusdiasystems eines bestimmten Gebiets im oberdeutschen Raum. Ein vollständiger und differenzierter historischer Überblick würde eine ausführliche Analyse historischer Primärquellen verlangen. 5 Dass die historische Überlieferung - insbesondere in den älteren Sprachstufen - größtenteils von der Schriftlichkeit aus hoch- beziehungsweise oberdeutschen Gebieten geprägt ist (vgl. etwa Sonderegger 1979: 142-145 zu geographischen Ausgangspunkten der althochdeutschen Überlieferung), kommt dieser Arbeit, die ja den geographischen Schwerpunkt im Oberdeutschen hat, jedoch sicher zugute. 
Flexion durch vorangestellte Determinierer (dem grünen Baum) (vgl. etwa Sonderegger 1979: 241-247). Dieses Prinzip wird durch das Auftreten sowie die Grammatikalisierung des definiten und indefiniten Artikels und damit den Ausbau des linken Randes der Nominalklammer verstärkt (vgl. beispielsweise Dal/Eroms 2014: 95-104, Oubouzar 1997, Szczepaniak 2016, Ronneberger-Sibold 2010b: 103-104).

Bedingt durch diese verschiedenen Markierungsprinzipien, die im deutschen System parallel auftreten und kongruenzbasierte Klammerstrukturen bilden, wird Kasus daher an verschiedenen Positionen innerhalb der Nominalphrase markiert - ein typologisch spezielles Charakteristikum, auf das ich in 2.2.2.2 näher eingehen werde. Die Flexionsparadigmen historischer Grammatiken (Braune/Heidermanns 2018, Ebert et al. 1993, Paul et al. 2013, Häckel/Walch 1988, Solms/Wegera 1991; Wegera/Moser 1987; Klein et al. 2018) bilden Muster der Kasusmarkierung für Nomen, Pronomen, Demonstrativa sowie teilweise für Indefinitpronomen, Interrogativpronomen und Possessivpronomen ab. Mit dem Aufkommen des Definitartikels im Verlauf des Althochdeutschen und dessen Ausbau begleitet vom Aufkommen des Indefinitartikels ab mittelhochdeutscher Zeit bilden sich zwei zusätzliche kasustragende Wortarten heraus, deren Paradigmen in den oben angeführten Grammatiken (mit Ausnahme von Braune/Heidermanns 2018) nachgezeichnet werden, während die regressive Flexion insbesondere am Nomen zunehmend abgebaut wird (Sonderegger 1979: 245-248).

Ein Vergleich der Flexionsparadigmen in historischen Grammatiken ermöglicht es, die Muster dieser kasustragenden Wortarten zu vergleichen und deren historische Entwicklung grob zu skizzieren. Sonderegger (1979: 250-253) beschreibt diese Entwicklung im deutschen Kasussystem als zunehmende Nivellierung - d. h. als zunehmenden formalen Distinktionsverlust - des ursprünglichen germanischen Systems, für das, abhängig von Wortart, Numerus und Deklinationsklasse, bis zu sechs Kasus angesetzt werden können, die sich über ihre jeweilige syntaktische Funktion im Sprachsystem beschreiben lassen, wie dies im Folgenden anhand von Sonderegger (1979: 98-99) illustriert ist: Neben dem Nominativ als Subjekt- und Prädikativkasus existiert ein Vokativ zur nominalen Anrede. ${ }^{6}$ Der Akkusativ markiert das direkte Objekt sowie räumliche Ausdehnung und Richtung, der Dativ das indirekte Objekt sowie „Zweck“ und „innere Beteiligung“ (Sonderegger 1979: 99). Der Genitiv wird als „Kasus des Bereichs“ (Sonderegger 1979: 98) charakterisiert und dient insbesondere der

6 Der Status des Vokativs als eigenständiger Kasus wird in neueren Arbeiten jedoch teilweise angezweifelt, vgl. dazu z. B. Blake (2001: 8). 
Markierung von Possessiv und Partitiv. Daneben existiert noch ein Instrumental, der dem Namen entsprechend sowohl das Mittel als auch die Funktion der Begleitung ausdrückt.

Im Neuhochdeutschen sind Instrumental und Vokativ nicht mehr als synthetische Kasus vorhanden. Es werden noch ein bis maximal vier standarddeutsche Kasus - Nominativ, Akkusativ, Dativ und Genitiv - unterschieden. Schirmunski (1962: 411-414), ausführlicher jedoch Mironow (1957: 390-391), nennen verschiedene Phänomene, die den Nivellierungsprozess der Kasusmarkierung vom germanischen System bis zum Neuhochdeutschen begleiten beziehungsweise unterstützen.

Phonologische Prozesse - hier wird zentral die Nebensilbenabschwächung angeführt - reduzieren insbesondere das Inventar der Flexionsformen des Substantivs, wodurch es dort zum Zusammenfall von vormals distinkten Kasusformen kommt. Über analogische Prozesse können sich die neuen synkretischen Strukturen ausweiten (vgl. Mironow 1957: 390, Hotzenköcherle 1962b: 327-328, Schirmunski 1962: 411-414), was für eine zusätzliche Morphologisierung der ursprünglich phonologisch bedingten Kasusnivellierung spricht (vgl. dazu Baechler/Pröll 2018: 4).

Das Aufkommen bestimmter analytischer Muster - wie etwa von Kasusmarkierung durch Periphrasen und präpositionale Elemente - wird ebenso als Faktor angeführt, der die Nivellierung synthetischer Kasus begünstigt. Dies betrifft insbesondere periphrastische Konstruktionen (dem Florian sein Haus, das Haus von bzw. vom Florian) zum Ausdruck von Possessiven, die zuvor ausschließlich durch synthetische Genitivkonstruktionen (Florians Haus) markiert wurden (vgl. Mironow 1957: 390).

Die Ausprägungen des abstrakten Kasus im germanischen System, die hier mit Sonderegger (1979) angesetzt werden, weisen in der Entwicklung zum Neuhochdeutschen jeweils unterschiedliche Tendenzen zur Nivellierung beziehungsweise zur Distinktion auf. Während der Vokativ lediglich im Gotischen belegt ist - und dessen Funktion später vom Nominativ übernommen wird (vgl. Sonderegger 1979: 99), wird der Instrumental noch relikthaft in $\mathrm{Pa}-$ radigmen des Althochdeutschen (vgl. etwa Braune/Heidermanns 2018: 246350) aufgeführt. In mittelhochdeutschen Paradigmen finden sich dagegen nur noch vereinzelte Reste davon (vgl. etwa Paul et al. $2013 \mathrm{zu}$ Paradigmen des neutralen Demonstrativpronomens und Definitartikels); in späteren Sprachstufen ist er nicht mehr als funktionsfähiger und formal distinkter synthetischer Kasus belegt. Seine Funktion wird nun von einer Dativperiphrase übernommen (vgl. Sonderegger 1979: 99).

Nominativ und Akkusativ weisen über die gesamte Entwicklung des Deutschen hinweg eine starke Tendenz zum formalen Zusammenfall auf. Mit Aus- 
nahme des Personalpronomens der 1. und 2. Person zeigen sie im Plural bereits im Althochdeutschen keine formale Distinktion (vgl. etwa Braune/Heidermanns 2018: 243-350). Für das Neutrum sind auch im Singular bei keiner Wortart und in keiner deutschen Sprachstufe distinkte Nominativ- und Akkusativformen belegt und auch im Femininum Singular findet sich eine Distinktion der beiden Kasus nur bis zum Mittelhochdeutschen (vgl. Braune/Heidermanns 2018, Paul et al. 2013 und Klein et al. 2018). In den frühneuhochdeutschen Paradigmen (vgl. Solms/Wegera 1991, Solms/Wegera 1993, Wegera/Moser 1987, und Häckel/ Walch 1988) ist diese Distinktion bereits nicht mehr belegt.

Die Distinktion von Nominativ und Akkusativ, die für das Neuhochdeutsche angesetzt wird, basiert folglich ausschließlich auf maskulinen Relationen (vgl. etwa auch Dal 1971a: 187). Allerdings gibt es - geographisch begrenzt auch im Maskulinum erste Indizien für ein Eindringen der Nivellierungstendenz. Dal (1971a: 187) und Hotzenköcherle (1962b: 328) beschreiben für das Alemannische sowie für weitere hochdeutsche Dialekte entlang des Rheins eine Formengleichheit von Nominativ und Akkusativ beim maskulinen Definitartikel. Es ist möglich, dass sich diese Tendenz bereits in der Beobachtung von Häckel/Walch (1988: 184) andeutet, die auf vereinzelte Belege von Formengleichheit zwischen Nominativ und Akkusativ beim maskulinen Demonstrativpronomen (vgl. Häckel/Walch 1988: 184) und beim maskulinen Definitartikel (vgl. Häckel/Walch 1988: 191) im Frühneuhochdeutschen hinweisen. Hier deutet sich an, dass die geographisch begrenzte Ausdehnung dieses Musters unter Umständen bereits in frühneuhochdeutscher Zeit eingesetzt hat.

Die zunehmende Nivellierung des synthetischen Genitivs bildet das wahrscheinlich prominenteste Beispiel von Kasusnivellierung. Historische Grammatiken zeigen hier zwar - verglichen mit der Nivellierungstendenz von Nominativ und Akkusativ - nur wenige Belege für formalen Zusammenfall mit einem anderen Kasus bis in die frühneuhochdeutsche Zeit, der Rückgang des Genitivs in bestimmten Funktionen - der sich damit nicht ausschließlich durch Formennivellierung erklären lässt - wird allerdings recht häufig beschrieben (vgl. etwa Behaghel 1923, Mironow 1957, Schirmunski 1962, Koß 1983, Donhauser 1998).

Dabei sind zwei Funktionen des Genitivs zu unterscheiden, die eine unterschiedliche Entwicklung aufweisen: Der adverbale Genitiv, der etwa die Funktion des Genitivobjekts ausdrückt (Sie freut sich des Kuchens), ist bereits recht früh geschwunden und dessen Funktion wurde zumeist durch präpositionale Akkusativ- (Sie freut sich über den Kuchen) oder Dativperiphrasen (Sie freut sich an dem Kuchen) ersetzt (vgl. etwa Mironow 1957: 393). Donhauser (1998) führt zwei mögliche innergrammatische Szenarien für diesen Schwund an, die beide über eine rein phonologisch bedingte Formennivellierung hinausgehen und als Ursache für den Verlust unterschiedlicher Ausprägungen des Geni- 
tivs infrage kommen. Der Genitivschwund (zugunsten des Akkusativs) bei zweiwertigen Verben lässt sich nach Donhauser (1998: 83) auf den Verlust der Aspektkategorie zurückführen. Der Genitiv, der zuvor mit einer imperfektiven Lesart einhergegangen war, wurde bei den diesen Verben mit Verlust der Differenzierung verschiedener aspektueller Lesarten durch den Akkusativ ersetzt, welcher zuvor der perfektiven Lesart vorbehalten war (vgl. Donhauser 1998: 70-79). Für dreiwertige Verben, bei denen eine aspektuelle Lesart des Genitivs zu keiner Zeit möglich war, geht Donhauser (1998: 81-83) vom Verlust eines lexikalisch gesteuerten Genitivs aus, der nicht durch das Szenario des Aspektverlusts zu erklären ist.

Der adnominale, possessive Genitiv, der die syntaktische Funktion eines Attributs markiert (der Pullover des Großvaters), ist zwar in der neuhochdeutschen Standardsprache noch vorhanden, gilt allerdings in den modernen deutschen Dialekten - mit Ausnahme einiger isolierter Varietäten - als bis auf wenige relikthafte Konstruktionen ausgestorben und wird dort, wie auch teilweise in der Standardsprache, durch verschiedene Periphrasen, die sich auf synthetische Dativformen stützen, ersetzt (vgl. etwa Mironow 1957: 393, Behaghel 1923: 638-639). Hier lassen sich von-Periphrasen (der Pullover von meinem Großvater) von possessiven Dativen (meinem Großvater sein Pullover) unterscheiden (vgl. zur Terminologie Fleischer/Schallert 2011: 94-99). Fleischer/Schallert (2011: 94-99) zeichnen die Entwicklungsprozesse der beiden Periphrasen aus der Reanalyse einer Präpositionalphrase (von-Periphrase) beziehungsweise einer dativischen Phrase, auf die eine weitere Nominalphrase folgt (possessiver Dativ), nach.

Eine vertiefende Diskussion der verschiedenen Verdrängungsprozesse des synthetischen Genitivs wird an dieser Stelle allerdings nicht angestrebt, da der Genitiv sowie damit verbundene Periphrasen in der hier vorgestellten Arbeit eine untergeordnete Rolle spielen (vgl. 2.2.2.3).

Der Dativ zeigt im Gegensatz zu den anderen bisher angeführten Kasus eine vollkommen andere Entwicklung: Dal (1971a: 188) sieht die historische Entwicklung des Dativs als wichtiges Abgrenzungsmerkmal der hochdeutschen Dialekte von den übrigen germanischen Sprachen und Dialekten an und geht so weit, das Hochdeutsche aufgrund seiner starken Tendenz zur distinkten Dativmarkierung als „Dativgebiet“ (Dal 1971a: 189) zu charakterisieren. Die starke Stellung des distinkten Dativs sieht sie hier durch mehrere Phänomene gewährleistet: Zum einen handelt es sich bei der Akkusativ-Dativ-Distinktion um ein häufiges Muster (vgl. Dal 1971a: 188), das in allen Genera und zu großen Teilen im Plural der meisten kasustragenden Wortarten über alle Sprachstufen hinweg in historischen Grammatiken belegt ist. Zum anderen nennt sie die Ausdehnung des Funktionsspektrums beim Dativ als möglichen Grund für den formalen Erhalt der Dativdistinktion. So übernimmt ja der Dativ in periphrastischen Formen zahl- 
reiche Funktionen anderer, früher synthetisch ausgedrückter Kasus, wie etwa die des Instrumentals und des Genitivs (Dal 1971a: 188).

Neben dem Erhalt der synthetischen Dativdistinktion weist Dal (1971a: 189193) zudem u. a. auf ein Phänomen des formalen Ausbaus beim Dativ hin. Dieses ist zwar nicht unbedingt für den in dieser Arbeit beschriebenen Dialektraum relevant, zeigt aber dennoch einen interessanten Aspekt der Erhaltungstendenzen in den hochdeutschen Dialekten auf und stützt die These von einem funktionalen und formalen Ausbau des Dativs im hochdeutschen Gebiet: die präpositionale Dativmarkierung, eine Verstärkung der Dativmarkierung durch ein zusätzliches präpositionales Element, das die synthetische Dativdistinktion zumeist ergänzt.

Die präpositionale Dativmarkierung erinnert zwar formal an eine Präposition (z. B. in oder an), muss aber nach der Analyse von Seiler (2003: 225-226) ,als reines Kasuszeichen angesehen werden“ (Seiler 2003: 226). ${ }^{7}$ Eine Tendenz zum Synkretismus von Akkusativ und Dativ beim maskulinen Definitartikel (der [Nom]/ den [AKK]/dem [DAT] wird hier etwa zu der [Nom]/den [AKK]/den [DAT]), die teilweise in ostoberdeutschen Dialekten auftritt, führt Dal (1971a) hingegen auf rein phonologische Entwicklungen zurück. Im Gegensatz zu Mironow (1957: 403), der dieses Muster als phonologisch gestützten Zusammenfall der Funktionen von Akkusativ und Dativ wertet, sieht Dal (1971a: 188) hier keinen strukturellen Einfluss auf die funktionale Distinktion von Akkusativ und Dativ.

Anhand dieser Tendenz zum Erhalt der Dativdistinktion argumentiert Dal (1971b: 177) dafür, dass durchaus gegenläufige Tendenzen zur Kasusnivellierung in der Entwicklung des deutschen Flexionssystems zu erkennen sind. Sie damit argumentiert anders als beispielsweise Hotzenköcherle (1962b: 327), der die Nivellierung der Kasusdistinktionen als derart starke Tendenz beschreibt, dass er sogar den vollständigen Relevanzverlust der Kategorie Kasus im Neuhochdeutschen vorhersagt. Der Ausbau des Dativs, den Dal (1971a) beschreibt, spricht jedoch für eine durchaus noch funktionsfähige morphologische Kasuskategorie in den hochdeutschen Systemen. Unter Berücksichtigung kasusmorphologischer Phänomene neuhochdeutscher Nicht-Standardvarietäten ${ }^{8}$ teilt Dürscheid (2007) die Nivellierungstendenzen in zwei Kategorien ein: die erste betrifft die Muster der Kasusmarkierung im jeweiligen Kontext, die zweite die abstrakten Kasus. Auch sie kommt zu dem Schluss, dass die abstrakten Kasus

7 Als Beispiel führt Seiler (2003: 15) nach Ströbl (1970: 66) das folgende Beispiel an: du muasst es a deinà frau verschraibn làssn, wobei er $a$ als präpositionalen Dativmarker der dativischen Nominalphrase deiná frau markiert.

8 Damit sind im Sinne Dürscheids (2007) Varietäten gemeint, die nicht der Standarddefinition nach Ammon (1995) entsprechen, aber überregional gebraucht werden. 
- zumindest die für das Neuhochdeutsche angesetzten - durchaus eine lebendige Kategorie bilden. Nivellierungstendenzen setzt sie primär auf der Ebene der Kasusdistinktion in einzelnen grammatischen Kategorien und damit auf Ebene der Muster der Kasusmarkierung an (Dürscheid 2007: 110).

\subsubsection{Formaler Ausdruck von Kasus}

Auf Basis der sprachhistorischen Beschreibung lassen sich für das (ober)deutsche System erste Erkenntnisse beziehungsweise Erwartungen zur formalen Markierung von Kasus im Paradigma formulieren, aus denen sich wiederum erste Ansatzpunkte für eine weitere Untersuchung ableiten lassen: Es können die synthetischen Kasus Nominativ, Akkusativ und Dativ angesetzt werden. Ein synthetischer Genitiv ist hingegen in den untersuchten Systemen nicht mehr systematisch, sondern nur vereinzelt und relikthaft zu erwarten. Dabei sind die formalen Distinktionen dieser Kasus stark mit anderen grammatische Kategorien, wie Numerus, Person und Genus verknüpft: Sie sind im Singular deutlich stärker ausgeprägt als im Plural, wo Nominativ und Akkusativ - mit Ausnahme der Personalpronomen der 1. und 2. Person - zum formalen Zusammenfall neigen und damit lediglich der Dativ distinkt markiert wird. Im Singular finden sich distinkte Formen der Kasus insbesondere im Maskulinum, während das Femininum und Neutrum, ähnlich wie bereits für den Plural attestiert, zumeist lediglich einen distinkten Dativ aufweisen. Die Kategorie Kasus scheint demnach in gewisser Weise von den Kategorien Numerus, Person und Genus abhängig zu sein - ein Zusammenhang, der etwa von Aikhenvald/Dixon (1998) auf Basis sprachtypologischer Daten in Form einer Dependenzhierarchie beschrieben wurde. Wie genau sich diese Abhängigkeit in den einzelnen grammatischen Kontexten und Mustern innerhalb des untersuchten oberdeutschen Kasusdiasystems äußert, kann im Verlauf der späteren Korpusanalyse differenziert analysiert werden.

Die verschiedenen Prinzipien zur Positionierung der Kasusmarkierung - bedingt durch den Ausbau der Klammerstruktur im Deutschen - wurden bereits aufgezeigt. Typologisch lassen sich dadurch im Neuhochdeutschen angelehnt an die Terminologie in Blake (2001: 7) grundlegend zwei Arten der synthetischen Kasusmarkierung unterscheiden: Zum einen gibt es nach wie vor nominale Kasusmarkierung (bei Blake 2001: 7 „nominal case“). Hier wird Kasus am Nomen oder Pronomen, d. h. am Kopf der Nominalphrase selbst, markiert. Insbesondere im System der oberdeutschen Dialekte spielt die Kasusmarkierung am Nomen selbst allerdings in Folge der dort fortgeschrittenen Kasusnivellierung (vgl. 2.2.2.1) eine derart untergeordnete Rolle, dass sich diese Arbeit lediglich auf das Pronomen als Träger des nominalen Kasus konzentriert. Zudem findet sich im Deutschen konkordialer Kasus (bei Blake 2001: 7 „concordial case“). Dabei handelt es sich um 
eine Form der Kasusmarkierung, bei der die Eigenschaft des abstrakten Kasus durch Kongruenz vom eigentlichen Kopf auf andere Elemente innerhalb der Nominalphrase übertragen und damit auch an Adjektiven und Determinierern markiert werden kann (Blake 2001: 7). ${ }^{9}$ Bedingt durch das parallele Auftreten dieser Arten der Kasusmarkierung müssen bei einer vollständigen Analyse des Kasusdiasystems zahlreiche kasustragende Wortarten einbezogen werden: Personalpronomen, Possessivpronomen und -determinierer, definite und indefinite Artikel, Demonstrativpronomen, Adjektive, Indefinitpronomen und Reflexivpronomen. Diese Wortarten können dabei im System nicht ausschließlich durch das Verb regiert werden, und damit adverbalen Kasus zeigen, sondern auch, insbesondere bei periphrastischen Formen, adnominalen oder adpositionalen Kasus tragen, und damit von einem Nomen (vgl. etwa Possessivperiphrasen, wie etwa der Mutter ihr Kind) oder einer Präposition (sie radelt zur Brücke) regiert werden.

Kasus kann im Deutschen grundsätzlich sowohl durch synthetische als auch durch analytische Markierung ausgedrückt werden (2.2.2.1), ${ }^{10}$ wobei die Struktur der formalen Kasusmarkierung im Deutschen, wie bereits angedeutet, generell durch einen Abbau synthetischer Strukturen am Nomen selbst geprägt ist (vgl. Roelcke 2004: 150). Da in dieser Arbeit die Kasusmarkierung am Nomen selbst allerdings ohnehin eine untergeordnete Rolle spielt, werden die Kategorien von Synthese und Analyse (vgl. etwa Sapir 2014 [1921]: 135) hier zugeschnitten auf die Merkmale des untersuchten deutschen Systems gebruacht: Neben Pronomen (z. B. ihm) werden auch diejenigen Nominalphrasen als eher synthetisch gewertet, die flektierte Determinierer und Adjektive aufweisen (z. B. den großen Kuchen). Werden mehrere flektierende Determinierer und Nomen kombiniert, um einen einzigen abstrakten Kasus beziehungsweise eine Funktion auszudrücken (z. B. Possessivität in der Kuchen des Mannes), baut sich diese Konstruktion zwar aus einzelnen synthetischen Markierungen auf, wird als Ganzes hier aber als analytisch begriffen. Enthält die Konstruktion eine Präposition, die u. U. mit

9 Blake (2001: 8) verweist darauf, dass auch Adjektive und Determinierer zur Nominalklasse gehören. Da diese laut Blake (2001: 7) jedoch durchaus konkordialen Kasus tragen und sich damit in Bezug auf die Form der Kasuszuweisung von den prototypischen Nominalkategorien unterscheiden, werden sie hier als eigene Subklasse gewertet.

10 Diese Aussage basiert auf der Definition der Kasusmarkierung als distinktem formalen Ausdruck der abstrakten Kasus. Shrier (1965: 436) hingegen - um ein Beispiel zu nennen - zählt analytische Strukturen, die abstrakten Kasus ausdrücken, nicht direkt zur Kasusmarkierung. Bezüglich analytischer Strukturen in oberdeutschen Dialekten schreibt sie: „But these new devices, [. . . ] can hardly be termed ,case' in the same way that -er,-en, and -em are cases. Rather, what is expressed through morphology in the standard language is often expressed in the dialect through syntax. The same distinctions, however, are maintained, in both speech forms" (Shrier 1965: 436). 
einer synthetischen Markierung kombiniert wird (z. B. die Torte vom Bäcker), werden diese Konstruktionen hier als eher analytisch gewertet (vgl. dazu etwa Blake 2001: 9-12 zum System des Lateinischen). Insbesondere bei den periphrastischen Konstruktionen, die beispielsweise den synthetischen Genitiv ersetzen (das Fahrrad von Max), aber auch beim Ausdruck von räumlichen und zeitlichen Relationen (Ich fahre in die Stadt), muss der Einfluss der Präposition, d. h. eine Form der adpositionalen Kasusmarkierung, berücksichtigt werden.

Da periphrastische Possessivkonstruktionen synthetische Formen enthalten, aber gemeinsam eine analytische Konstruktion bilden, folglich recht komplex aufgebaut sind, lohnt es sich, diese in einer separaten Analyse zu betrachten und dort dann sowohl die einzelnen synthetischen Bausteine als auch die analytische Konstruktion im Gesamten $\mathrm{zu}$ untersuchen. Da diese Arbeit paradigmatische Strukturen fokussiert, liegt der Schwerpunkt hier auf der synthethischen Kasusmarkierung.

Durch die Vielfältigkeit der kasustragenden Wortarten deutet sich an, dass verschiedene morphologische Strukturen an der Kasusmarkierung im deutschen System beteiligt sind. Einzelne kasustragende Wortarten lassen sich in unterschiedliche Typen der Kasusmarkierung gliedern, die unterschiedliche Grade der Irregularität (vgl. etwa Corbett 2007, Dammel 2008) und damit unterschiedliche morphologische Strukturen aufweisen. Diese Grade reichen im Standarddeutschen von relativ transparenter Affigierung bei Adjektiven (schön-en Tag) über weniger transparente Formen, wie etwa definite und indefinite Artikel (der/den), bis hin zu suppletiven Strukturen, wie etwa bei Personalpronomen (ich/mich/mir) (vgl. Ellsäßer 2019). Die Untersuchung einzelner kasusmarkierender Morpheme, wie etwa von Suffixen, reicht daher nicht aus, um das vollständige Spektrum der kasusmarkierenden Strukturen im deutschen Sprachsystem zu analysieren, weshalb in 3.3.1 dafür argumentiert wird, eher holistische Wortformen, die Kasus tragen, und damit Kasusformen, als Ausgangspunkt für die Analyse zu nutzen. Daher wird dort für eine grundlegend wortbasierte anstatt einer morphembasierten Ausrichtung (vgl. Stewart 2016: 5) der Analyse argumentiert.

Wie sich bereits in der historischen Übersicht an einigen Stellen (etwa in Bezug auf Phänomene der Dativmarkierung oder die Nivellierung von Nominativ und Akkusativ beim Definitartikel) angedeutet hat, zeigen die Muster der innerhalb des oberdeutschen Raums unterschiedliche Tendenzen, die zu geographisch determinierten Systemunterschieden führen. Daher wird in dieser Arbeit eine strukturelle Analyse der Kategorie Kasus im oberdeutschen System mit einer geographischen Analyse verknüpft. Auf diese Weise können nicht nur unterschiedliche Muster der Kasusmarkierung auf Basis der morphophonologischen Oberflächenstruktur abgebildet werden; es kann auch untersucht werden, inwiefern sich bestimmte historisch gewachsene Tendenzen, etwa 
die starke Stellung des hochdeutschen Dativs, in den räumlichen Strukturen der dialektalen Kasussysteme widerspiegeln.

\subsubsection{Funktionale Beschreibung von Kasus}

In 2.2.2.1 wurden die Kasus zunächst recht grob auf Basis der syntaktischen Funktionen nach Sonderegger (1979) abgegrenzt, was dem Umstand geschuldet ist, dass es ansonsten nur wenige Hinweise auf das Funktionsspektrum der Kasus in den älteren Sprachstufen gibt, die über kleinere Einzeluntersuchungen hinausgehen.

Für die funktionale Beschreibung von Kasus in rezenten Systemen können allerdings verschiedene Ansätze genutzt werden, die auf unterschiedlichen Beschreibungstraditionen beruhen. Die Ansätze basieren zumeist auf der Beschreibung einzelner Sprachsysteme und sind daher auf deren jeweilige Eigenschaften abgestimmt. Um sie auch für andere Systeme fruchtbar zu machen, ist es daher sinnvoll, sie zu kombinieren.

Der beispielsweise auch von Sonderegger (1979: 98-99) genutzte Ansatz definiert die Kasus über die jeweils damit ausgedrückten syntaktischen Funktionen und wird häufig in der „westlichen“ Tradition der Sprachbeschreibung genutzt, die in der Beschreibung des Lateinischen und Altgriechischen begründet ist (Blake 2001: 19-22). Eine detaillierte Übersicht über die syntaktischen Funktionen der neuhochdeutschen Standardsprache gibt etwa Dürscheid (1999: 25-42): Die im germanischen Kasussystem determinierten syntaktischen Funktionen sind zum größten Teil bis ins Neuhochdeutsche erhalten. Auf syntaktischer Ebene markiert der Nominativ im Standarddeutschen vornehmlich die Subjektposition, wobei er u. a. auch Prädikativa und - bedingt durch die Nivellierung des synthetischen Vokativs - die Vokativfunktion ausdrücken kann. Der Akkusativ markiert vornehmlich das direkte Objekt und der Dativ das indirekte Objekt. Sowohl Akkusativ als auch Dativ können adverbiale Bestimmungen, Präpositionalobjekte und Adjunkte markieren (vgl. Dürscheid 1999: 25-42).

Wie bereits ausführlich dargestellt, stellt der Genitiv einen Sonderfall dar. In der deutschen Standardsprache ist sein Funktionsspektrum stark im Rückgang begriffen. Der Genitiv tritt hier häufig nur noch in adnominalen Relationen (insbesondere in adnominaler Possessivität, z. B. der Oma ihr Kuchen), als Prädikativ (sich seiner Sache sicher sein) und in präpositionalen Fügungen (statt des starken Regens) auf (vgl. Dürscheid 1999: 34). In den dialektalen Kasussystemen, damit auch im hier untersuchten Teil des Oberdeutschen, gilt der synthetische Genitiv als vollständig getilgt bzw. als auf wenige formelhafte Kontexte beschränkt (vgl. etwa Dal 1971b: 173-174). Dort werden die hier genannten Funktionen in der Regel durch Dativperiphrasen ausgedrückt. 
Diese Beschreibung der abstrakten Kasus über die syntaktischen Funktionen eignet sich, so Blake (2001: 3), um einen bestimmten Teil des Funktionsspektrums der Kasus zu beschreiben, der zwar die grundlegenden Funktionen der Kasus abdeckt, aber insbesondere die lokalen Relationen, wie etwa räumliche und zeitliche Verortung, nicht explizit fassen kann. So lassen sich durch die Unterscheidung von Adverbialen und Attributen zwar syntaktische Relationen beschreiben, wie etwa der Argumentstatus einer Phrase. Deren tatsächliche Funktion und damit auch der damit verbundene Kasus lassen sich so aber nicht bestimmen (sowohl Akkusativ- als auch Dativphrasen können etwa ein Attribut sein). Blake (2001: 3) argumentiert, dass sich eben diese Relationen eher durch semantische Rollen differenzieren lassen können.

Die Differenzierung der semantischen Rollen kann, je nach Tradition und Notwendigkeit im zu beschreibenden Sprachsystem, unterschiedlich feinkörnig angesetzt werden. Primus (1999), die sich mit diesem Ansatz in Bezug auf das Standarddeutsche beschäftigt, wählt dabei die recht grobkörnige Einteilung in semantische Proto-Rollen nach Dowty (1991). Diese Einteilung basiert auf dem Konzept der Prototypentheorie, in der Kategorien, in diesem Fall semantische Rollen, zu Ähnlichkeitsclustern zusammengefasst werden, die einem Prototypen, d. h. dem Ideal einer semantischen Rolle, unterschiedlich ähnlich sind (Primus 1999: 3). Sie wählt dabei drei Proto-Rollen für die Beschreibung des deutschen Sprachsystems - Proto-Agens, Proto-Patiens und Proto-Rezipient.

Eisenberg (2013: 74) setzt unter Bezug auf Primus (1999) den prototypischen Zusammenhang von semantischer Rolle, syntaktischer Funktion und Kasus im standarddeutschen System wie folgt an: In der prototypischen Konstellation drückt ein Subjekt im Nominativ das Proto-Agens und ein direktes Objekt im Akkusativ das Proto-Patiens aus. Soweit vorhanden, wird ein weiteres Argument - (Primus 1999) bezeichnet es als Proto-Rezipienten - durch ein indirektes Objekt im Dativ ausgedrückt (z. B. Die Konditorin [Proto-Agens, Nom, Subjekt] backt ihr [Proto-Rezipient, DAT, indirektes Objekt] einen Kuchen [ProtoPatiens, AKK, direktes Objekt]). Handelt es sich - so Eisenberg (2013: 74) - um weniger typische Proto-Rollen, kann der Dativ etwa das Proto-Agens oder ProtoPatiens ausdrücken und der Nominativ den Proto-Rezipienten (z. B. Sie bekommt einen Kuchen von der Konditorin oder Der Kuchen wird ihr weggegessen).

Das Funktionsspektrum der einzelnen Kasus in Bezug auf den Ausdruck der semantischen Rollen variiert folglich je nach dem im Satz auftretenden Verb (sowie der Diathese) (Eisenberg 2013: 69). Die Beschreibung dieses Spektrums orientiert sich damit stark an der Argumentstruktur des Satzes und damit an den syntaktischen Kernfunktionen des Systems. Sprachtypologische Arbeiten gehen hier so weit, die Typologisierung von Kasussystemen ausschließlich an diesen Kernfunktionen festzumachen und diese basierend auf einem System 
einzuteilen, das ursprünglich auf die Beschreibung australischer Sprachen in Dixon (1972) zurückgeht und, etwa in Mallinson/Blake (1981: 41), als „DixonSystem" bezeichnet wird.

Dabei werden lediglich drei Argumente unterschieden, die als grammatische Kernfunktionen bezeichnet werden: A als agentivischeres Argument eines transitiven Satzes, $\mathrm{P}$ als patientivischeres Argument eines transitiven Satzes und S als einziges Argument eines intransitiven Satzes (vgl. etwa Mallinson/ Blake 1981: 41, Comrie 1981: 119). Im Deutschen, das nach dieser Klassifikation als Nominativ-Akkusativsprache determiniert ist, werden A und $\mathrm{S}$ durch denselben Kasus, nämlich den Nominativ, ausgedrückt, P hingegen durch einen Akkusativ. Im folgenden Beispiel wird eine solche Konstellation illustriert: Dabei zeigt (1) einen intransitiven Satz, dessen einziges und damit agentivischstes Argument die Mutter ebenso durch einen Nominativ ausgedrückt wird wie das agentivischere Argument die Großmutter in (2). Das dort auftretende passivischere Argument wird mit den Kuchen im Akkusativ ausgedrückt.

(1) Die Mutter (S) isst.

(2) Die Großmutter (A) isst den Kuchen (P).

Die Kasus, die diese Kernfunktionen ausdrücken, werden als Kernkasus bezeichnet. In Fällen von ditransitiven Relationen werden die Kasus beider weniger agentivischer Elemente zu den Kernkasus gezählt. Für das Deutsche ergeben sich nach dieser Definition drei mögliche Kernkasus: Nominativ, Akkusativ und Dativ. Der im Verlust begriffene synthetische Genitiv kann als peripherer Kasus bezeichnet werden, da er (bis auf das selbst in der Standardsprache seltene Genitivobjekt) keine dieser Kernfunktionen mehr markiert. Diese Einteilung orientiert sich an den grundlegenden, in Blake (2001: 32) als „primär“ bezeichneten, Funktionen der Kernkasus. Das oben erwähnte Problem des so nur schlecht greifbaren Ausdrucks von räumlicher und zeitlicher Verortung, das ja im (Ober-)Deutschen ebenso zum erweiterten Funktionsspektrum der als Kernkasus auftretenden Kasus Akkusativ und Dativ gehört, lässt sich durch diese Kernfunktionen allerdings nicht spezifizieren.

Diese Funktionen, die teilweise als „Lokalrollen“ (vgl. dazu Bierwisch et al. 1988, Jackendoff 1995, Lestrade 2010) bezeichnet werden, sind allerdings für die vollständige Beschreibung des Funktionsspektrums im oberdeutschen Kasussystem notwendig. Kasper/Werth (2015: 352), die sich mit dialektaler Argumentstruktur im Deutschen beschäftigen, gliedern diese in das Spektrum der Proto-Rollen in Form einer Proto-Location ein, die die semantischen Rollen EXTENT, SOURCE, GOAL und Duration umfasst und damit auf Ebene der semantischen Rollen das vollständige Funktionsspektrum der sekundären Funktionen 
von Akkusativ (z. B. den ganzen Tag) und Dativ (vom Wald her) im Deutschen beschreiben kann.

Die Funktionen, die in Entwicklungen im deutschen Kasussystem für die jeweiligen Kasus angesetzt wurden, insbesondere die Kernfunktionen, die die Argumentstruktur determinieren, werden im deutschen Sprachsystem nicht ausschließlich durch Kasus, sondern auch durch syntaktische Muster, wie etwa bestimmte Wortstellungsvarianten, oder durch semantische Phänomene, wie etwa Belebtheitspräferenzen bestimmter Rollen, disambiguiert. Diese gemeinsame Funktion kann eine Interaktion der Phänomene untereinander verursachen. Bei einer eindeutigen Zuordnung der semantischen Relationen durch Syntax oder Semantik stellt die Kasusmarkierung ein redundantes Merkmal dar und wird womöglich, bedingt durch Ökonomisierungsprozesse, abgebaut. Die folgenden Kapitel enthalten daher einen kurzen Überblick über bisherige Erkenntnisse zur Interaktion der Kategorie Kasus mit der Ebene der Syntax und der Semantik.

\subsubsection{Funktionale Interaktion mit der Syntax}

Wie bereits angemerkt, bildet insbesondere die eindeutige Markierung der Argumentstruktur einen Ausgangspunkt für die Untersuchung der Interaktion von syntaktischen Phänomenen mit der Kategorie Kasus. Damit stehen hier die Kernfunktionen (S, A und P) sowie die Kernkasus, die diese ausdrücken, im Zentrum. Das syntaktische Phänomen, das die Eindeutigkeit dieser Markierung neben einer distinkten Kasusmarkierung zum Ausdruck bringen kann, ist die Serialisierung - und damit die Annahme, dass das Subjekt prototypischerweise dem Objekt bzw. ein agentivischeres Element einem weniger agentivischen vorausgeht (vgl. zum Deutschen etwa Primus 1999: 133).

Die Annahme eines Zusammenhangs von Kasusmarkierung und freier oder fester Wortfolge ist in verschiedenen Traditionen der Linguistik verbreitet (vgl. beispielsweise Meillet 1922 [1917], Keenan 1978, Comrie 1981, Hawkins 1986). Relevant ist diese Form der Interaktion für die Beschreibung des oberdeutschen Kasussystems dann, wenn ein direkter Zusammenhang beziehungsweise ein Einfluss der syntaktischen Muster auf die Muster der Kasusmarkierung nachgewiesen wird - wenn etwa eine gewisse Abfolge von Argumenten als Auslöser für bestimmte Muster der Markierung von Kernkasus oder gar als Ursache für eine Variation verschiedener Muster im einzelnen System nachgewiesen werden kann.

Zum Zusammenhang von Mustern in Serialisierung und Kasusmarkierung finden sich bereits erste dialektologische Arbeiten, die sich größtenteils sogar auf ein oberdeutsches System - wenn auch nicht auf das dieser Korpusanalyse beziehen. Werlen (1990: 170) attestiert etwa für das Alemannische nicht nur das bereits oben eingeführte Muster von Nominativ-Akkusativ-Synkretismus auch im 
Maskulinum, sondern zusätzlich eine feste Subjektposition innerhalb des Satzes - vor dem Objekt. Er argumentiert, dass diese feste Position ausreiche, um das Subjekt distinkt zu markieren und distinkte Nominativ- und Akkusativformen damit nicht notwendig seien. Damit deutet er einen direkten durch Ökonomisierung begründeten Zusammenhang zwischen Kasussynkretismus und einer festen Serialisierung an. Seine Argumentation ist allerdings nicht empirisch gestützt, sondern baut lediglich auf einzelnen introspektiven Beispielen aus seiner eigenen Kompetenz auf.

Dass es zwar einen gewissen, aber keinesfalls derart eindeutigen und kausalen Zusammenhang zwischen bestimmten Mustern der Kasusmarkierung und solchen der Serialisierung gibt, legen weitere, empirisch fundierte Arbeiten zu diesem Thema nahe. So können etwa Siewierska (1998) in einer Studie zur Wortfolge europäischer Sprachen und Rauth (2016: 129-132) in einer Untersuchung zur Abfolge von Objekten in ditransitiven Relationen der deutschen Dialekte keinen signifikanten Zusammenhang von Kasussynkretismus und Serialisierungsfixierung feststellen. Siewierska (1998) weist in einem Vergleich von 171 europäischen Sprachen allerdings einen gewissen Zusammenhang zwischen Kasusdistinktion innerhalb bestimmter Systeme und relativer Wortfolgefreiheit in denselben Systemen nach. Ein ähnlicher Zusammenhang zeigt sich in einer Pilot-Untersuchung zur Interaktion von Kasusmarkierung und Wortfolgemustern im Alemannischen und Ostfränkischen: Hier hat sich immerhin eine gewisse Korrelation von distinkt markierten Nominativformen und der nicht-prototypischen Objekt-vor-Subjekt-Abfolge gezeigt (vgl. Ellsäßer 2015). Rauth (2016) weist nach, dass die hochdeutschen Kasussysteme, die maximal drei Kasus und damit häufig auch Akkusativ und Dativ unterscheiden, eher zur nicht-prototypischen Abfolge von DO und IO neigen als die niederdeutschen Dialekte, die maximal zwei Kasus, und eben nicht Akkusativ und Dativ, distinkt markieren.

Diese Ergebnisse lassen annehmen, dass die Distinktion von Subjekt und direktem Objekt - und damit von Nominativ und Akkusativ - und die Distinktion von direktem und indirektem Objekt - und damit von Akkusativ und Dativ durchaus eine Interaktion mit bestimmten Serialisierungsmustern aufweisen. $\mathrm{Ob}$ hier allerdings ein kausaler Zusammenhang besteht und inwiefern sich diese Interaktion formal, etwa in Mustern der Kasusmarkierung bestimmter Wortarten, äußert, kann auf Basis der bisherigen Arbeiten nicht ermittelt werden.

\subsubsection{Funktionale Interaktion mit der Semantik}

Ähnlich wie für die Syntax beschrieben, ist auch ein gewisser Einfluss der Semantik auf die Kasusmarkierung zu vermuten. Dabei stellt insbesondere die Belebtheit eine interessante Kategorie dar. Belebtheit wird dabei - basierend ursprünglich 
auf einer Arbeit von Silverstein (1976), die sich passenderweise mit einem belebtheitsinduzierten Split morphologischer Muster in australischen Sprachen beschäftigt - hierarchisch differenziert. Während Silversteins (1976) ursprüngliche Belebtheitshierarchie mit [HumAN] > [ANIMATE] > [INANIMATE] die eigentliche Distinktion von Belebtheitsstufen enthält, sind dort auch weitere, später zunehmend davon getrennt betrachtete Skalen enthalten; nämlich eine Personenhierarchie - [1./2. PS] > [3. PS] - und eine referentielle Hierarchie [PRONOMEn] > [EIGENnAmE] > [GATTUnGSNAme] (Silverstein 1976: 122, vgl. dazu etwa auch Croft 2006: 130). Je nach Notwendigkeit in der Systembeschreibung kann die Belebtheitshierarchie unterschiedlich feinkörnig aufgegliedert sein. Belebtheit bildet eine fundamentale Kategorie für die Markierung der Argumentstruktur. Yamamoto (2010: 149-150) etwa beschreibt die intrinsisch-lexikalische Eigenschaft der Belebtheit als semantische Grundlage der Agentivität, die er als intentionale - und damit prototypische - Handlung eines ebenso belebten Referenten definiert. Damit ist die semantische Kategorie der Belebtheit nicht nur - wie etwa die Serialisierung - ein Muster zur formalen Distinktion der grammatischen Kernfunktionen, sondern bildet vielmehr deren semantisch-lexikalischen Ausgangspunkt.

Angelehnt an Bank (2007) und Krifka (2009) beschreiben Alber/Rabanus (2011) den Zusammenhang von Kasussynkretismus und Belebtheit in Bezug auf die Markierung der Argumentstruktur anhand germanischer Pronominalparadigmen: Während das Nomen im Nominativ, das das Agens bzw. das Subjekt innerhalb einer transitiven Relation ausdrückt, prototypischerweise belebt ist, kann das Patiens bzw. Objekt hier sowohl durch ein belebtes als auch ein unbelebtes Nomen im Akkusativ besetzt sein. Prototypischerweise ist die Patiensbzw. Objektposition allerdings mit einem unbelebten Nomen besetzt. Tritt in einer solchen Relation jedoch ein belebtes und damit nicht-prototypisches Nomen in der Patiens- bzw. Objektposition auf, kann eine distinkte Markierung des Akkusativs als prototypischer Objektskasus eine eindeutige Zuordnung gewährleisten (Alber/Rabanus 2011: 32).

Es besteht daher die Annahme, dass insbesondere die Abweichung von prototypischen Zusammenhängen bei Kernkasus, etwa unbelebte Referenten im Nominativ und belebte Referenten im Akkusativ, einen Einfluss auf die Variationsmuster der Kasusmarkierung ausübt - ein Konzept, das bereits in zahlreichen Arbeiten und häufig als „differentielle Objektmarkierung“ angeführt wird (Aissen 2003, Comrie 1981: 120-129, Mallinson/Blake 1981: 62, Yamamoto 2010: 45-52). Auch wenn sich diese These mit Alber/Rabanus (2011) nicht statistisch verifizieren lässt, gilt es, diesen Aspekt im Rahmen einer Analyse des oberdeutschen Kasusdiasystems auch für Wandel- und Variationsprozesse zu überprüfen. 
Erste Untersuchungen konnten für bestimmte oberdeutsche Dialekte bereits eben diesen Zusammenhang zwischen nicht-prototypischen Belebtheitsrelationen und intrasystematischer Variation in den Mustern der Kasusmarkierung nachweisen. Dal Negro (2004), deren Arbeit sich mit dem Artikelsystem der Südwalser Dialekte beschäftigt - d. h. einem System, das zwar ebenfalls zu den oberdeutschen Dialekten gehört, aber deutlich südlicher als das hier untersuchte Gebiet liegt -, beschreibt einen Verstärkungsprozess in der im System zuvor getilgten Nominativ-Akkusativdistinktion. Im Kasussystem des Ortes Issime gilt diese Distinktion bereits als getilgt (beide werden durch eine dar-Form ausgedrückt). Dennoch lassen sich einzelne Formen finden, die auf eine historisch belegte Akkusativform (da, dan) zurückgehen (vgl. Dal Negro 2004: 108). Dal Negro (2004: 108-110) argumentiert nun, dass sich die ursprünglich zur Kasusdistinktion genutzten Formen in eine referentielle Distinktion umgewandelt haben, in der unbelebte Nomen mit der historischen Akkusativdistinktion und belebte Nomen mit der ehemaligen Nominativdistinktion bezeichnet werden.

Inwiefern hier tatsächlich eine vollständige Umfunktionierung von vollständig verlorenen Kasusformen stattfindet, ${ }^{11}$ kann hier nicht erschöpfend geklärt werden. Der Beschreibung von oberdeutschen Kasussystemen fügt diese Beobachtung allerdings zwei weitere interessante Aspekte hinzu, die es bei einer Untersuchung zu berücksichtigen gilt:

Erstens scheint es tatsächlich einen recht direkten Einfluss semantischer Hierarchien auf die Kategorie Kasus und deren formalen Ausdruck zu geben. Die spezifische Rolle dieses semantischen Einflusses in der historischen Entwicklung, aber auch in der synchronen strukturellen Gliederung des Kasussystems, gilt es in jedem Fall zu überprüfen.

Zweitens fügt sie eine erste Erkenntnis über die Art des Einflusses der funktionalen Interaktion nicht-morphologischer Kategorien bei. Neben Wandelphänomenen, die das System kontextübergreifend erfassen, können diese Einflüsse auch zu partiellem systematischen Wandel, der das System nicht vollständig ergreift, führen, der damit nicht in jedem Kontext durchgeführt ist und der sich in Formen von intrasystematischer Variation niederschlägt. Diese ist dabei als Variation zwischen zwei verschiedenen Mustern der Kasusmarkierung im selben System definiert. Dabei könnte beispielsweise in einem Kontext, in dem die Argumentstruktur durch prototypische Argumente besetzt ist, bei der damit ein belebtes, agentivisches Subjekt vor einem unbelebten, patientivischen Objekt steht, ein Synkretismus der Nominativ- und Akkusativform auftreten, während im

11 Eine vertiefende Diskussion dieser These findet sich in Simon (2010). 
selben System in einem Kontext, in dem weniger prototypische Argumente auftreten, eine Distinktion dieser beiden Formen zu finden ist.

In dieser Arbeit unterscheide ich dabei zwischen intrasystematischer und idiolektaler Variation. Während sich die intrasystematische Variation lediglich auf ein nicht näher spezifiziertes Kasussystem, wie etwa das des Ortes Issime in Dal Negro (2004), beziehen lässt und damit eine gewisse Abstraktion über mehrere Idiolekte darstellt, äußert sich idiolektale Variation auf Basis des Kasussystems einzelner SprecherInnen. Die Ursache intrasystematischer Variation kann daher auch auf der sprecherInnenspezifischen Variation zwischen den einzelnen im System abstrahierten Idiolekten liegen. Bei der idiolektalen Variation lässt sie sich hingegen im Idiolekt selbst verorten (vgl. Ellsäßer 2020). ${ }^{12}$

\subsubsection{Zwischenfazit}

Dieses Kapitel hat zunächst die terminologischen Grundlagen der Arbeit geklärt. Kasus wurde dabei als multidimensionale Kategorie beschrieben, die sowohl eine abstrakte, funktionale Ebene als auch eine formale Ebene umfasst. Den Zugriffspunkt einer Korpusanalyse von Kasussystemen bildet dabei die formale, spezieller die morphophonologische Ebene. Sie zeigt sprachstufen- und sprachraumspezifische Unterschiede (2.2.2.1). Anhand einer kurzen Skizze der historischen Entwicklungen des deutschen Kasusdiasystems wurde die Entwicklung der verschiedenen Ebenen der

bis zum Neuhochdeutschen hin nachgezeichnet. Dabei hat sich gezeigt, dass andere morphologische Kategorien wie Person, Genus und Numerus den formalen Ausdruck von Kasus beeinflussen und dass verschiedene Wortarten in unterschiedlicher Ausprägung an der Kasusmarkierung beteiligt (2.2.2.2) und damit für eine vollständige Beschreibung des Kasussystems relevant sind.

Zudem hat sich angedeutet, dass Kasus, bedingt durch die gemeinsame Funktion beim Ausdruck der Argumentstruktur (2.2.2.3), eine gewisse Interaktion mit Wortfolgemustern (2.2.2.4) und Stufen der Belebtheitshierarchie (2.2.2.5) aufweist. Für die angestrebte Untersuchung scheint es daher unumgänglich, diese morphologischen, syntaktischen und semantischen Einflüsse als Variablen in die Analyse der Kasussysteme zu integrieren.

12 Dabei ist natürlich zu berücksichtigen, dass - insbesondere im Kontext der dialektalen Kasussysteme - auch bei der idiolektalen Variation Einflüsse von verschiedenen standardnäheren und standardfernen Sprechlagen der EinzelsprecherInnen nie auszuschließen sind. 


\subsection{Kasus in der Dialektgeographie}

Im vorigen Kapitel wurden erste Erkenntnisse zur grundlegenden Struktur des oberdeutschen Kasusdiasystems beschrieben. Ähnlich wie bereits für die diachrone Entwicklung beschrieben, hat das Kapitel dabei zunächst eine Abstraktion der geographischen Variation vorgenommen. Es hat sich jedoch bereits dort abgezeichnet, dass bestimmte diachrone Entwicklungsschritte innerhalb der Kasusmorphologie nur Teile des Gebiets ergriffen haben und in anderen Teilen unterblieben sind. Es ist deshalb anzunehmen, dass sich auch das in dieser Arbeit untersuchte Kasusdiasystem keinesfalls als durchgängig homogen erweist, sondern vielmehr kleinräumige Teilsysteme enthält.

Ziel ist es nun, zu ermitteln, welche Eigenschaften das untersuchte Diasystem als solches konstituieren und welche in einzelnen diatopisch determinierten Teilsystemen abweichen und damit raumbildend sind. Das Kapitel widmet sich dazu zunächst einem Überblick über Forschungsstand, Methoden und Erkenntnisse der kasusmorphologischen Dialektgeographie.

German linguistic geography has concentrated on phonology and vocabulary; if morphology has been considered at all, the regional fate of isolated morphemes has been plotted without reference to the systems in which these morphemes function.

(Shrier 1965: 420)

Wenngleich diese Aussage von Shrier (1965) zum Forschungsstand der dialektgeographischen Untersuchung deutscher Kasussysteme über 50 Jahre alt ist und dieser in der Zwischenzeit durchaus um einige Arbeiten ergänzt wurde, hat die (Kasus-)Morphologie in der Dialektologie bei weitem nicht denselben Hype erfahren, der die Syntax (vgl. etwa Abraham/Bayer 1993, Glaser 1997, 2008, Fleischer et al. 2012, Speyer/Rauth 2016) in den letzten Jahren geprägt hat. Birkenes (2014: 22) sieht diesen Umstand in den Interessensschwerpunkten der beiden für die moderne Dialektologie prägenden Forschungstraditionen begründet: Während traditionelle Dialektologie sich lange primär auf Phonologie und Lexik konzentriert hat, war die theoretische Linguistik lange Zeit stark syntaktisch orientiert. Die Morphologie hat hingegen in beiden Disziplinen über Jahrzehnte einen generell eher untergeordneten Stellenwert eingenommen - ein Status, der sich durch das aufkeimende morphologische Interesse der theoretischen Linguistik langsam wandelt (vgl. dazu beispielsweise Stewart 2016, Dammel/ Schallert 2019).

Neben einer Übersicht über die bislang entstandenen Arbeiten zur dialektgeographischen Kasusmorphologie und deren Erkenntnissen zur räumlichen Gliederung oberdeutscher Teilsysteme hat dieses Kapitel daher auch zum Ziel, die theoretische Einbettung sowie die typischen Arbeitsweisen und -schwerpunkte zu skizzieren, die das kleine Forschungsfeld bislang geprägt 
haben. Dabei werden neben ersten inhaltlichen Erkenntnissen, die sich aus diesen Arbeiten zu den Kasussystemen im Untersuchungsgebiet dieser Arbeit ableiten lassen, auch theoretische und methodische Schlüsse für die später beschriebene dialektgeographische Untersuchung gezogen.

\subsubsection{Bisherige Arbeiten und deren theoretische Fundierung}

Den Ausgangspunkt dieser Übersicht bilden all diejenigen Arbeiten, deren Ergebnisse Anspruch auf einen mehr oder weniger größeren Raum im oberdeutschen Gebiet erheben und damit Aufschluss über geographische Strukturen der Kasusmorphologie versprechen und sich - im optimalen Fall - auf das hier untersuchte Gebiet beziehen lassen. Die Arbeit von Shrier (1965) bildet dabei die bislang einzige flächendeckende Untersuchung dialektaler Kasussysteme im deutschsprachigen Raum. Die Arbeit beschäftigt sich mit Mustern der Kasusmarkierung im gesamten deutschen Sprachgebiet und behandelt mehrere für die Kasusmarkierung relevante Wortarten und Genera im Singular. Ihre Alleinstellungsmerkmale sind folglich zum einen in der geographischen Breite, zum anderen in der ausführlichen strukturellen Betrachtung des Kasussystems zu sehen. Damit bietet Shrier (1965) einen bis heute unübertroffen breiten Überblick über die Verbreitung bestimmter Muster der Kasusmarkierung im deutschsprachigen Raum. Ihre Arbeit kann damit als Grundlagenarbeit auf dem Gebiet der kasusmorphologischen Dialektgeographie begriffen werden. Die herausragende Stellung der Arbeit innerhalb des Forschungsfelds wird zudem durch den Umstand untermauert, dass sie zahlreichen weiteren Arbeiten, die sich zum Teil eher am Rand mit dialektalen Kasussystemen beschäftigen, zugrunde liegt (z. B. Koß 1983, Rowley 1997, 2004, Howe 1996 und Rauth 2016). Anhand von Kasusparadigmen in 55 Dialektgrammatiken untersucht Shrier (1965) definite und indefinite Artikel, Personal- und Demonstrativpronomen sowie starke Adjektive (Shrier 1965: 420). Dabei handelt es sich zwar nicht um eine erschöpfende Betrachtung aller kasustragenden Wortarten des gesamten Kasusdiasystems. Ein derart großer Ausschnitt erlaubt jedoch erste Schlüsse auf allgemeinere Tendenzen und Mechanismen.

Da sich neben Shrier (1965) bezüglich der geographischen Verbreitung keine weiteren Arbeiten vollständig auf das für die Korpusanalyse in dieser Arbeit untersuchte Gebiet beziehen, erfolgt an dieser Stelle auch ein Blick auf die Untersuchungen zu Kasussystemen in angrenzenden ober- bzw. hochdeutschen Räumen. Die Arbeit von Rabanus (2008) betrachtet Synkretismus und Distinktion in hochdeutschen Dialekten in einem bestimmten Kontext: einem „Minimalsatz" bestehend aus einem Personalpronomen und einem intransitiven Verb. 
In diesem Rahmen gibt Rabanus (2008) auch einen geographischen Überblick über pronominale Kasussysteme, der für seine Arbeit von Interesse ist. Dabei finden sich dort auch Erkenntnisse zu Personalpronomen in Gebieten (BayerischSchwaben und südliches Baden-Württemberg), die sich teilweise mit dem hier untersuchten Areal überschneiden.

Die Kasusmorphologie der Artikel wird in zwei Arbeiten auf dem Gebiet der deutschsprachigen Schweiz und damit im hoch- und höchstalemannischen Raum untersucht. Meyer (1967) beschreibt die Verbreitung verschiedener Formen der definiten und indefiniten Artikel, aus denen sich auch die dort auftretenden Muster der Kasusmarkierung rekonstruieren lassen. Auch Perrig (2018) konzentriert sich geographisch hauptsächlich auf die deutschsprachige Schweiz ${ }^{13}$ und widmet sich primär der Artikelmorphologie und daneben auch der Morphologie der Adjektive. Ihre Untersuchung berücksichtigt dabei nur einen Ausschnitt des Kasussystems: die Markierung von Nominativ und Akkusativ. Neben der geographischen Verbreitung von Synkretismus und Distinktion dieser beiden Kasus widmet sie sich auch einem diachronen Überblick über die Entwicklung dieser Muster in den schweizerdeutschen Dialekten und einer möglichen Interaktion mit dem Schweizer Hochdeutschen.

Aber auch kleinräumigere Untersuchungen beziehungsweise Analysen kleinerer Systemausschnitte werden hier berücksichtigt: Die Arbeit von Rowley (1997) zur Nominalflexion in Dialekten im Nordosten des Bundeslands Bayern sowie die von Seiler (2003) zum bereits erwähnten Phänomen des Ausbaus der formalen Dativdistinktion, der präpositionalen Dativmarkierung, im Alemannischen und Bairischen gehen in die folgende Übersicht ein. Rowley (2004) ergänzt die Ergebnisse von Shrier (1965) für kleinräumige Gebiete im Westoberdeutschen vereinzelt um weitere Daten und wird daher, soweit möglich, an den relevanten Stellen zur Übersicht herangezogen.

Bezüglich der theoretischen Ausrichtung bisheriger Arbeiten sowie der daraus resultierenden Desiderate lassen sich zwei Schwerpunkte abgrenzen: Die strukturell interessierte Beschreibung der Systemfunktion - die auf die Muster der Kasusmarkierung, d. h. auf die Funktion der einzelnen Formen im kasusmorphologischen System, abzielt - und die Formbeschreibung deren Ziel eher an der morphophonologischen Oberfläche zu verorten ist. Beide Schwerpunkte werden bereits von Shrier (1965) angesprochen, die sich explizit auf Seite der Systemfunktion positioniert - ein weiterer Aspekt,

13 Die deutschsprachige Schweiz bildet in Perrig (2018) das geographische Kerngebiet. Zudem nutzt sie allerdings auch Daten, die Auskunft über Gebiete außerhalb der Schweiz geben, wie etwa den Vorarlberger Sprachatlas (vgl. Perrig 2018, 96-99). 
der bereits in ihrer kritischen Auseinandersetzung mit dem Forschungsstand im oben angeführten Zitat auffällt ${ }^{14}$ und der sich in die Tradition der strukturellen Dialektologie (vgl. insbesondere Weinreich 1954, später beispielsweise auch Goossens $1969^{15}$ ) einbinden lässt:

In seinem Grundlagenartikel stellt Weinreich (1954) ein Konzept vor, mit dem sich strukturalistische Ideen auf die dialektologische Untersuchungen anwenden lassen. Ziel ist eine strukturelle Dialektologie, die Weinreich (1954) am Beispiel phonologischer Strukturen und Formen der Pluralbildung konzeptualisiert. Dabei führt er mehrere Desiderate an, von denen sich zwei in Bezug auf Shriers (1965) Arbeit als besonders relevant erweisen: Zum einen kritisiert er die in vielen „traditionell“16 dialektologischen Arbeiten bloße Abbildung von Unterschieden einzelner Teilsysteme ohne den Hinweis auf die gemeinsamen konstituierenden Muster des Diasystems (Weinreich 1954: 391). Zum anderen sieht er die Notwendigkeit, bei einer geographischen Untersuchung dieser Teilsysteme nicht nur einzelne Formen - die „Substanz“ - zu vergleichen, sondern vielmehr die Funktionen dieser Formen innerhalb des jeweiligen Teilsystems zu berücksichtigen und einen Vergleich unter Berücksichtigung dieser Funktionen anzustellen (Weinreich 1954: 392).

In Shrier (1965) lässt sich nun ein Ansatz erkennen, diese Desiderate auf die dialektgeographische Untersuchung der Kasusmorphologie zu übertragen. Abgesehen von einer direkten persönlichen Danksagung an Uriel Weinreich (Shrier 1965: 420) spiegelt auch das theoretische Grundgerüst diese beiden Desiderate der strukturellen Dialektologie wider: ${ }^{17}$ Anstatt sich ausschließlich auf die Unterschiede der einzelnen Teilsysteme zu konzentrieren, beschreibt Shrier (1965) ausführlich die konstituierenden Muster des deutschen Kasusdiasystems, wie beispielsweise die maximale Ausprägung der abstrakten Kasus (Shrier 1965: 421) und den generellen Status der Kategorie Kasus (Shrier 1965: 431) sowie die grundlegenden konstituierenden Eigenschaften eines nördlichen und südlichen Kasusdiasystems (Shrier 1965: 431-432). Insbesondere das von Weinreich (1954: 392) aufgestellte Desiderat, die Funktion

14 „[. . . ] the regional fate of isolated morphemes has been plotted without reference to the systems in which these morphemes function" (Shrier 1965: 420).

15 Die folgenden Ausführungen zur strukturellen Dialektologie sowie zu deren Bezug zu Shrier (1965) stützen sich ausschließlich auf die Arbeit von Weinreich (1954).

16 Den Begriff der traditionellen Dialektologie, die hier im Gegensatz zur strukturellen Dialektologie steht, nutze ich angelehnt an Niebaum/Macha (2014: 77-78).

17 Bereits Rowley (1997: 19) rechnet Shrier (1965) (neben etwa Panzer 1983 und Lipold 1983) in einer kurzen Aufzählung der strukturalistischen Dialektologie zu, führt diesen Aspekt jedoch nicht weiter aus. 
von Formen anstatt ihres bloßen Ausdrucks als Ausgangspunkt für einen Vergleich von Teilsystemen zu nutzen, stellt Shrier (1965), wie bereits im obigen Zitat angeführt, explizit ins Zentrum ihrer Untersuchung:

The primary emphasis in this paper is on functions within a system; specifically, the paper concentrates on case distinctions in the grammatical system of a geographical region. The concrete shape of case markers is a secondary consideration. (Shrier 1965: 420)

Grundlage des Vergleichs dialektaler Teilsysteme ist damit die Funktion, die einzelne Formen für den distinkten oder synkretischen Ausdruck abstrakter Kasus innerhalb einer Wortart in einem grammatischen Kontext tragen. Diese Systemfunktion lässt sich mit dem Begriff des Musters der Kasusmarkierung, den ich in 2.2.1 definiert habe, gleichsetzen. Um diese Funktion vollständig zu beschreiben, wird jeweils das gesamte Muster einer grammatischen Kategorie berücksichtigt. Innerhalb der paradigmatischen Repräsentation bezieht sich die Analyse folglich auf eine vollständige Reihe von Zellen, die die morphophonologische Oberflächenstruktur aller abstrakten Kasus abbildet, d. h. je eine Form für Nominativ, Akkusativ und Dativ (und Genitiv im Standarddeutschen) innerhalb einer einzigen grammatischen Kategorie (vgl. dazu Abb. 3).

\begin{tabular}{l|l|l|l} 
Nominativ & Akkusativ & Dativ & Genitiv \\
\hline eine & eine & einer & einer \\
\hline \multirow{2}{*}{ Zelle } & Zelle & Zelle & Zelle \\
& & & \\
\hline
\end{tabular}

Reihe

Abb. 3: Paradigmatische Reihen und Zellen am Beispiel des standarddeutschen femininen Indefinitartikels.

Die Systemfunktion spiegelt sich in Shriers (1965) Analyse nun in dem Grad wider, in dem die Formen dieser Reihe zum Ausdruck der abstrakten Kasus beitragen: Beim Beispiel des femininen Indefinitartikels in Abb. 3 würde man folglich von einem Muster mit synkretischen Nominativ- und Akkusativformen bei einer distinkten Dativ- und Genitivform sprechen. Im geographischen Vergleich werden hier ausschließlich diese Muster für verschiedene grammatische Kategorien in den einzelnen Teilsystemen beschrieben und einander jeweils systemübergreifend gegenübergestellt. Shrier (1965) bezieht die morphophonologische Oberflächenstruktur, die bei Weinreich (1954: 392) als „Substanz“ bezeichnet wird, ausschließlich mit ein, um zu definieren, welche abstrakten Kasus an 
einer Stelle im System unterschieden werden (Shrier 1965: 431). Damit folgt sie der lateinisch-griechischen Tradition der Linguistik (vgl. etwa Blake 2001: 19-20).

Auch Rabanus (2008) richtet seine Fragestellung grundlegend an der Systemfunktion der von ihm untersuchten Pronominalformen aus. Neben einer Beschreibung von (vollständigen) Mustern der Kasusmarkierung folgt dort auch eine ausgiebige Beschreibung der Formen im Paradigma; wobei zudem auch formale Eigenschaften genannt werden, die nicht unbedingt für die Systemfunktion relevant sind (Rabanus 2008: 151-153 und 188-196).

Rowley (1997) bezieht sich explizit auf die Tradition der strukturellen Dialektologie in der Morphologie (Rowley 1997: 18-19) und nennt die Muster innerhalb des Paradigmas als Vergleichsgrundlage morphologischer Systeme (Rowley 1997: 24-25). Innerhalb der Beschreibung der arealen Gliederung der Systeme selbst finden sich allerdings neben diesen funktionalen Aspekten auch ausführliche Beschreibungen der morphophonologischen Oberflächenstruktur (Rowley 1997: 171-174), die teilweise nicht, teilweise durchaus funktionsrelevant sind. Der Schwerpunkt der rein funktionalen Beschreibung ist hier folglich ebenfalls nicht derart konsequent umgesetzt wie etwa bei Shrier (1965).

Die Fragestellung in Seiler (2003) ist grundlegend an der Ebene der Systemfunktion beziehungsweise der abstrakten Kasus orientiert: Sie fokussiert einen bestimmten Teilaspekt des Systems, nämlich die formale Markierung des abstrakten Dativs. $\mathrm{Zu}$ einem gewissen Teil ist die Konzeption der Analyse zwar auch an der nicht-funktionsrelevanten formalen Beschreibung der Konstruktion in den einzelnen untersuchten Gebieten und damit an der morphophonologischen Oberflächenstruktur orientiert (vgl. beispielsweise Seiler 2003: 39-40). Grundlegendes Ziel der Untersuchung ist jedoch nicht die Beschreibung vollständiger Muster, sondern die Analyse der Systemfunktion der präpositionalen Dativmarkierung in den einzelnen untersuchten Gebieten (vgl. etwa Seiler 2003: 15-16). Im Gegensatz zu Shrier (1965) bezieht sich Seiler (2003) zur Ermittlung der Systemfunktion auf keine vollständige paradigmatische Reihe, sondern analysiert lediglich die einzelne Zelle innerhalb dieser Reihe, die den formalen Ausdruck des Dativ trägt ein Vorgehen, das sich für Seilers (2003) Fragestellung durchaus anbietet, das aber bei einer vollständigen Analyse von Kasusdiasystemen, wie sie hier angestrebt ist, ein Problem birgt: Ohne die Distinktion von allen anderen angesetzten abstrakten Kasus in der paradigmatischen Reihe lässt sich die Systemfunktion der einzelnen Zelle beziehungsweise die der darin enthaltenen Wortform ohne zusätzliches Datenmaterial nicht eindeutig bestimmten. Dies lässt sich an einem Beispiel illustrieren: In einem Teilsystem kann etwa die Wortform de den Akkusativ des maskulinen Definitartikels markieren (vgl. beispielhaft Tab. 2); in einem anderen kann dieselbe Form sowohl die Zellen des Akkusativs als auch die des Nominativs in dieser Kategorie besetzen (vgl. beispielhaft Tab. 3). 
Tab. 2: Paradigmatische Reihe des maskulinen Definitartikels nach Wagner (1987: 81).

\begin{tabular}{ll}
\hline abstrakter Kasus & Wortform \\
\hline Nominativ & der \\
\hline Akkusativ & $d e$ \\
\hline Dativ & $e m$ \\
\hline Genitiv & $s$ \\
\hline
\end{tabular}

Tab. 3: Paradigmatische Reihe des maskulinen Definitartikels nach Fischer (1999: 183).

\begin{tabular}{ll}
\hline abstrakter Kasus & Wortform \\
\hline Nominativ & de (auch der) \\
\hline Akkusativ & de (auch der) \\
\hline Dativ & em \\
\hline Genitiv & de (auch der) \\
\hline
\end{tabular}

Damit erfüllen die Formen zwar verschiedene Funktionen innerhalb der Teilsysteme, ein Vergleich auf Basis der Formen würde diese jedoch als identisch klassifizieren und den Systemunterschied damit verschleiern (vgl. zur Diskussion dieser Problematik etwa Weinreich 1954: 392-393). Methodisch ließe sich ein rein formenbasiertes Vorgehen lediglich durch einen großen Vorwissenstand $\mathrm{zu}$ den untersuchten Teilsystemen umgehen: Wenn demnach die Systemfunktion der Kasusformen aller grammatischer Kategorien eines Teilsystems bekannt wären und Systemunterschiede zwischen den einzelnen Teilsystemen ausgeschlossen werden könnten. Für ein solches Vorwissen kann der aktuelle Forschungsstand der kasusmorphologischen Dialektgeographie jedoch keinesfalls als ausreichend betrachtet werden, weshalb eine Analyse vollständiger paradigmatischer Reihen für einen Vergleich von Teilsystemen unumgänglich scheint.

Ebenso wie Seiler (2003) konzentriert sich auch Perrig (2018) nicht auf die vollständige paradigmatische Reihe, sondern auf lediglich zwei Zellen: Nominativ und Akkusativ. Dabei hat ihre Arbeit zwar die Analyse distinkter und synkretischer Muster dieser beiden Zellen zum Ziel - was auch ausführlich beschrieben und diskutiert wird -, verglichen mit den zuvor genannten Arbeiten legt sie allerdings auch einen recht starken Schwerpunkt auf die exakten Formen der einzelnen Zellen sowie die geographische Verbreitung eben dieser Formen. Dies 
spiegelt sich insbesondere auch in der Gestaltung der Karten (vgl. Perrig 2018: 284-301) wider, die stark an der Kartierung formaler Ausdrucksformen orientiert sind und funktionale Differenzen eher untergeordnet wiedergeben.

Auch das Interesse von Meyer (1967) liegt stärker auf der formalen Beschreibung der Oberflächenstruktur (vgl. etwa Meyer 1967: 11); die Funktionsbeschreibung ist dieser auch hier eher untergeordnet. Seine Ausführungen und Karten konzentrieren sich ausschließlich auf die phonologische beziehungsweise morphologische Variation der Struktur der einzelnen Artikel. Diese werden zwar aufgegliedert nach den verschiedenen abstrakten Kasus beschrieben, die Diskussion über die Relevanz dieser Wortformen für das Kasussystem erfolgt ausschließlich auf Grundlage der Erkenntnisse zur den verschiedenen formalen Ausprägungen in den einzelnen Gebieten (vgl. Meyer 1967: 119).

Im kurzen Überblick über die theoretische Fundierung der bisherigen Arbeiten hat sich ein eindeutiger Schwerpunkt auf der funktionalen Beschreibung von Kasussystemen in der dialektgeographischen Analyse abgezeichnet. Dabei finden sich, neben der Beschreibung beziehungsweise dem Vergleich dieser Muster auch teilweise Beschreibungen der morphophonologischen Oberflächenstruktur. Die streng strukturell orientierte Analyse aus Shrier (1965) wird demnach nicht in jeder Arbeit bis zur letzten Konsequenz repliziert; was mitunter daran liegt, dass eine rein morphologische Beschreibung von vollständigen Kasussystemen und der darauf basierende Vergleich von Teilsystemen nur selten Ziel der Analyse ist. Eben dies steht jedoch in dieser Arbeit im Fokus. Daher wird hier der strukturell-dialektologische Ansatz, wie er in Shrier (1965) dargestellt ist, zumindest beim Vergleich geographisch determinierter Teilsysteme, angestrebt.

Abgesehen von den Arbeiten, die nur einen bestimmten Ausschnitt des Kasussystems einer grammatischen Kategorie zum Ziel haben und sich daher auf einzelne paradigmatische Zellen konzentrieren (etwa Seiler 2003 und Perrig 2018), basiert der Vergleich einzelner Teilsysteme in den bisherigen Arbeiten jeweils auf der Analyse vollständiger paradigmatischer Reihen beziehungsweise den dort ermittelten Mustern der Kasusmarkierung - ein Vorgehen, das sich für die vollständige Analyse von Teilsystemen anbietet, über die wenig Vorwissen vorhanden ist, und daher auch in dieser Arbeit umgesetzt wird.

Wie sich in der Übersicht gezeigt hat, setzen die Untersuchungen zwar verschiedene Schwerpunkte auf bestimmte Ebenen der Kategorie Kasus, beziehen aber zumeist mehrere Ebenen in die Analyse mit ein, was in der lateinisch-griechischen Tradition, wo die abstrakten Kasus ja lediglich über die funktionale Interpretation der formalen Ausprägungen definiert werden, kaum vermeidbar ist. Die vollständige Trennung der einzelnen Ebenen der Kategorie Kasus muss daher wohl eher als theoretisches Desiderat betrachtet werden, das sich in einer empirischen Operationalisierung zwar anzustreben und in einer Interpre- 
tation zu trennen lohnt, das aber in der konkreten Analyse nicht unbedingt vollständig umgesetzt werden kann und im Kasusdiasystem wohl auch nicht in dieser Form zu finden ist.

\subsubsection{Methodik und Datenbasis bei der Untersuchung von Kasussystemen}

Als Ausgangspunkt für die Analyse von dialektalen Kasussystemen finden sich in bisherigen Arbeiten sowohl primäre als auch sekundäre Datenquellen. Im Folgenden werden die dort verwendeten Daten- und Untersuchungstypen kurz vorgestellt und deren Vor- bzw. Nachteile für die Analyse von Kasussystemen diskutiert.

Eine sekundäre Datenbasis hat den unbestreitbaren Vorteil einer großen, bereits mehr oder weniger aufgearbeiteten Datenmenge. Insbesondere in Bezug auf die großflächige geographische Verbreitung können hier schnell Erkenntnisse gewonnen werden, da die Daten bereits (teilweise) analysiert und strukturiert vorliegen. Um die Analyse sekundärer Daten nachvollziehbar zu gestalten, sollten jedoch die zugrundeliegenden Primärdaten und deren methodische Auswertung transparent gehalten werden. Grundlegend kann zwischen der Auswertung von Ortsmonographien und Dialektgrammatiken (siehe etwa Shrier 1965, Meyer 1967, Seiler 2003, Rabanus 2008 und Perrig 2018) und der von Sprach- bzw. Dialektatlanten (siehe etwa Meyer 1967, Rowley 1997, 2004 und Perrig 2018) unterschieden werden.

Durch Dialektatlanten lassen sich insbesondere aufgrund der bereits erfolgten geographischen Referenzierung schnell Erkenntnisse über die dialektgeographischen Strukturen größerer Räume gewinnen. Der in dieser Arbeit untersuchte Dialektraum wird von keinem solchen Atlas (mit Ausnahme des Sprachatlas' des Deutschen Reichs ${ }^{18}$ ) vollständig abgedeckt. Es finden sich allerdings kleinräumige geographische Übereinstimmungen mit dem Atlas zur Geographie

18 Dabei ist zu bemerken, dass sich keine der Karten des Deutschen Sprachatlas direkt mit kasusmorphologischen Phänomenen auseinandersetzt. Anhand der 40 Wenkersätze, die dem Deutschen Sprachatlas zugrunde liegen, könnten zwar vereinzelt bestimmte Muster von Kasusdistinktionen im Raum rekonstruiert, oder die Kasusformen nach Präpositionen, wie beispielsweise in jiddischen Wenkermaterialien in Fleischer/Schäfer (2014: 15-16) geschehen, analysiert werden, allerdings treten die relevanten Kasusformen hier in eher speziellen Kontexten auf (etwa maskuline Definitartikel, die für den Akkusativ ausschließlich in adpositionalen Konstruktionen belegt sind) und lassen damit keine vollständige Rekonstruktion der Kasussysteme zu. Ein vollständiges Paradigma ergäbe sich so nur für den Singular des maskulinen Personalpronomens, den maskulinen Definitartikel sowie den Singular und Plural des Personalpronomens der 2. Person. 
der schwäbischen Mundart (Fischer 1895), dem Sprachatlas von Bayerisch Schwaben (Zeisberger/Funk 2003), dem Sprachatlas von Mittelfranken (Klepsch et al. 2003) sowie dem Südwestdeutschen Sprachatlas (Steger et al. 1997). Ein geographisch vollständiges Bild würde sich auf Basis dieser Daten demnach durchaus rekonstruieren lassen; ein kasusmorphologisch vollständiges Bild hingegen nicht: Da Kasusmorphologie in diesen Atlanten zumeist eine untergeordnete Rolle spielt, werden nie alle kasustragenden Wortarten im System in Atlanten untersucht. Die Untersuchung von Ausschnitten des Kasussystems erfolgt zudem in den verschiedenen Atlanten nicht einheitlich. So behandeln etwa der Sprachatlas von Mittelfranken und der Südwestdeutsche Sprachatlas lediglich die Muster der Nominalflexion, die in dieser Arbeit ohnehin eine untergeordnete Rolle spielen, und konzentrieren sich dabei stark auf die Pluralmorphologie (vgl. Klepsch et al. 2003: 28-124, Steger et al. 1997). Lediglich der Sprachatlas von Bayerisch-Schwaben (insbesondere Band 9.2, Zeisberger/Funk 2003) beschäftigt sich mit der Verbreitung zahlreicher, für die Kasusmarkierung relevanter Wortarten (definite und indefinite Artikel, Possessivpronomen, Personalpronomen, Reflexivpronomen und Adjektive) und gibt in Band 9.2 zudem „Systemkarten“, die sich mit der Verbreitung der standardabweichenden Formengleichheit von Akkusativ und Dativ und damit mit dem Ausschnitt eines Musters der Kasusmarkierung beschäftigen (vgl. Zeisberger/Funk 2003: 179-201). Dieser Atlas hat allerdings nur wenige Überschneidungspunkte mit dem östlichen Teil des hier untersuchten Gebietes und lässt damit keine flächendeckenden Aussagen zu dessen Teilsystemen zu. Obwohl die Kasusmorphologie nicht im Fokus der hier angeführten Dialektatlanten steht, könnte eine tiefergehende Analyse aller Atlanten und von auch zum Teil unveröffentlichtem Material weitere Erkenntnisse zur geographischen Verbreitung einzelner kasusmorphologischer Muster ergeben.

So lassen sich etwa aus den Kartierungen der Artikelformen in Meyer (1967) Kasusdistinktionen sekundär aus dem Material des Sprachatlas der Deutschen Schweiz (Hotzenköcherle 1975) rekonstruieren. Inwiefern ein solches Vorgehen in Bezug auf das hier untersuchte Gebiet zielführend wäre, ist an dieser Stelle schwer zu beurteilen. Hier wäre immerhin Datenmaterial aus vier verschiedenen Dialektatlanten zugänglich und vergleichbar $\mathrm{zu}$ machen, um eine vollständige Abdeckung des Untersuchungsraums zu gewährleisten. ${ }^{19}$

19 Rowley (2004: 344) deutet eine gewisse Zugänglichkeit des nicht-veröffentlichen Materials oberdeutscher Atlanten an. Unter Berücksichtigung der oben genannten Einschränkungen wäre hier also durchaus eine breiter angelegte Untersuchung denkbar. 
Die zweite oben angeführte sekundäre Datenquelle, die Auswertung von Ortsmonographien und Dialektgrammatiken, verspricht, insbesondere in Bezug auf das westoberdeutsche Gebiet und damit für das für diese Analyse relevante Areal, eine sehr gute geographische Abdeckung (vgl. etwa Birkenes 2014 und Fischer 2018) und eine einfache Zugänglichkeit des Materials. ${ }^{20}$ Mit Bezug auf syntaktische Fragestellungen nennt Fleischer (2002: 36-37) die besonderen Vorteile von Dialektbeschreibungen, zu denen insbesondere die Ortsgrammatiken gezählt werden können: Es liegt hier bereits eine Interpretation oder zumindest eine Kommentierung der Daten vor, die überdies von ExpertInnen des entsprechenden Dialektraums vorgenommen worden ist. Vereinzelt können hier sogar Informationen darüber enthalten sein, ob ein Phänomen häufig oder eher relikthaft beziehungsweise in bestimmten Kontexten auftritt. Probleme sieht Fleischer (2002: 37) jedoch beim Versuch, ein einheitliches Ortsnetz auf Basis der Dialektbeschreibungen zu erstellen, da diese äußerst heterogen über das deutsche Dialektgebiet verteilt sind (Fleischer 2002: 36-37). Im Vergleich $\mathrm{zu}$ den bereits diesbezüglich aufbereiteten Belegen der Dialektatlanten ist hier zudem hinsichtlich der geographischen Referenzierung eine gewisse Mehrarbeit zu leisten (siehe dazu 3.2.1).

Auch die Frage der Vergleichbarkeit der einzelnen in den Grammatiken gewonnenen Belege gestaltet sich, bedingt durch die größere Menge an Ausgangswerken, komplexer als bei den Dialektatlanten. Die zugrundeliegenden Daten und die Methodik sind hier deutlich heterogener als in den großräumigeren, intern einheitlichen Atlasprojekten und können von Introspektion der AutorInnen über die Befragung einzelner Angehöriger bis hin zu groß angelegten Erhebungen mit mehreren Gewährspersonen variieren.

Ebenso unterschiedlich ist häufig auch der Aufbau und damit der wissenschaftliche Schwerpunkt der Arbeiten. Während Phonetik und Phonologie aufgrund der junggrammatischen Tradition dieser Werke (vgl. etwa Schmidt/Herrgen 2011: 90-92) in jeder Arbeit vertreten sind, sind syntaktische und morphologische Inhalte deutlich seltener angeführt. Innerhalb der Nominalmorphologie machen Beschreibungen von Pluralbildung und Genitivschwund einen größeren Teil der Darstellung aus (Birkenes 2014: 40).

Als problematisch erweist sich in den Grammatiken die häufig starke Orientierung am standardsprachlichen, mittelhochdeutschen oder teilweise lateinischen Paradigma. Kasusdistinktionen werden hier angelehnt an ein bereits vorhandenes Paradigma untersucht, das es auszufüllen gilt. Die grundlegend

20 Dialekt- und Ortsgrammatiken sind zwar in vielen, gut sortierten germanistischen Bibliotheken zugänglich. Einen deutlichen Zugewinn für die Datenquelle würde allerdings die zunehmend geforderte Digitalisierung bedeuten (vgl. dazu auch Schmidt et al. 2019). 
angenommenen abstrakten Kasus, deren formaler Ausdruck anhand der paradigmatischen Zellen beschrieben werden soll, basieren so auf einem anderen kasusmorphologischen System als dem untersuchten - ein Problem, das teilweise auch bei Erhebungen zu Sprachatlanten auftritt. Das genutzte Bezugssystem muss also bei der Arbeit mit Grammatiken berücksichtigt werden - wie es Schmidt/Herrgen (2011: 92-95) für die phonetische und Fischer (2019: 316) für die verbalmorphologische Auswertung anmerken.

Die starke Orientierung an einem historischen bzw. standardsprachlichen Bezugssystem kann insbesondere auch in der Kasusmorphologie dazu verführen, dass gewisse Formen (beispielsweise der synthetische Genitiv), die zwar in passiver Kompetenz oder aus der Standardsprache bekannt sind, die allerdings im dialektalen System nicht gemeinhin produziert werden, als Nennformen angeführt werden. Dies ist ein Problem, das im allgemeinen bei der Analyse von Kasussystemen anhand von Nennformen zu berücksichtigen ist. Das dialektale Kasussystem wird hier nicht als eigenes, mehr oder weniger unabhängiges System, das eigens determinierte Ebenen und Muster der Kasusmarkierung enthält, analysiert, sondern lediglich in Abhängigkeit zu einem anderen System beschrieben, was zu starken Interferenzen führen kann.

Zudem führen Dialektgrammatiken die einzelnen Kasusformen bis auf wenige Ausnahmen losgelöst vom Kontext auf (es handelt sich hier nicht um ein „Sprachkorpus im eigentlichen Sinne“ Fischer 2019: 317) und beziehen somit Faktoren, die Kasusdistinktion möglicherweise begünstigen, wie etwa Serialisierung oder Belebtheit, nicht in die Beschreibung des Systems mit ein. Einer nicht-kasusmorphologischen Ursache für intrasystematische Variation oder Muster der Kasusmarkierung im Allgemeinen etwa ist auf dieser Datenbasis nicht nachzugehen, sofern diese in der Grammatik nicht - wie in äußerst seltenen Fällen geschehen - explizit angesprochen wird. Trotz der hier angeführten Probleme nimmt die Analyse von Ortsmonographien und Dialektgrammatiken einen grundlegenden Stellenwert in der bisherigen Forschung zu dialektalen Kasussystemen ein; besonders deshalb, weil sie die alleinige Methode im Grundlagenartikel von Shrier (1965) darstellt.

Neben den oben ausführlich diskutierten sekundären Daten wurden auch primäre Daten in den bisherigen Arbeiten genutzt. Diese wurden in Form von direkten Erhebungen (Rabanus 2008, Seiler 2003, Rowley 1997), indirekten Erhebungen (Meyer 1967, Rabanus 2008, Rowley 1997, Perrig 2018) und der Analyse von tonaufnahmenbasierten Korpora (Rowley 1997, Meyer 1967) gewonnen.

Grundlegende Vor- und Nachteile von direkter und indirekter Erhebung bei syntaktischen und teilweise morphosyntaktischen Fragestellungen wurden bereits an verschiedenen Stellen diskutiert (beispielhaft seien hier Fleischer et al. 2012 und Fleischer 2017 genannt). Diese Methoden setzen, insbesondere bezüg- 
lich der Untersuchung von Kasussystemen, ein relativ umfangreiches Vorwissen über möglicherweise relevante Kontexte und Einflussfaktoren voraus, das für eine Analyse des vollständigen Kasusdiasystems zum derzeitigen Forschungsstand nicht gegeben ist. Zwar können, durch das Abfragen von Nennformen, ähnlich wie bei vielen Dialektgrammatiken geschehen, Paradigmen erfragt werden. Die Einbettung der Formen in einen breiteren sprachlichen Kontext oder Interaktion etwa mit nicht-morphologischen Faktoren kann nur bei einer bereits daraufhin angelegten Aufgabenstellung abgefragt werden. Zudem kann ein Einfluss des standarddeutschen Bezugssystems bei direktem Abfragen von Nennformen nicht vermieden werden.

Perrig (2018: 99-107) stellt eine Sekundärauswertung der indirekt erhobenen Daten des Syntaktischen Atlas der deutschen Schweiz (SADS) an, in der sie die Antworten auf bestimmte Fragen, die ursprünglich auf andere Phänomene abzielen, auf kasusmorphologische Phänomene hin untersucht. Dabei geht sie auch auf methodische Probleme einer solchen Sekundärauswertung ein. Insbesondere bei Übersetzungsfragen ergibt sich hier das Problem, dass sich weder der angestrebte abstrakte Kasus noch die übrigen Variablen so eindeutig kontrollieren lassen, wie man es sich möglicherweise von einer Fragebogenerhebung erhoffen würde. Weichen die Gewährspersonen von der Ausgangskonstruktion in der Übersetzung ab, besteht die Möglichkeit, dass die Belege kasustragender Wortarten, abstrakter Kasus oder anderer Konstruktionen von der Vorgabe abweichen oder sich der anvisierte phonologische Kontext ändert (vgl. Perrig 2018: 100). Solche Abweichungen können in einer Sekundärauswertung durch die Fragestellung zur eigentlichen Zielkonstruktion evoziert sein. Bei einer Erhebung, die hingegen explizit auf Phänomene der Kategorie Kasus abzielt, treten diese Probleme unter Umständen seltener auf.

Bei der Analyse eines recht eng gefassten Phänomens, wie es etwa in Seiler (2003) mit der präpositionalen Dativmarkierung vorliegt, oder bei der Untersuchung einzelner Ausschnitte des Kasussystems, wie etwa bei Rabanus (2008) und Rowley (1997), kann eine direkte bzw. indirekte Erhebung also durchaus zielführend sein. Mit Blick auf die breitere Analyse des vollständigen Kasusdiasystems reicht der bisherige Forschungsstand allerdings nicht dazu aus, eine entsprechende Erhebung zu konzipieren.

Hier kann ein großer Vorteil der Korpusanalyse verortet werden: Anstatt von Nennformen können Belege für Kasusformen in spontaner Sprache und in verschiedenen Kontexten analysiert werden (vgl. dazu auch Fleischer 2002: 39 zu phonetisch transkribierten Dialekttexten). Das für eine solche Analyse zunächst relativ geringe notwendige Vorwissen kann im Verlauf der Untersuchung ausgebaut und rückwirkend auf das bereits vorhandene und annotierte Datenmaterial angewandt werden. Findet sich hier beispielsweise ein auffälli- 
ges Muster der Kasusmarkierung, können ohne größere Eingriffe in den grundlegenden Aufbau der Untersuchung verschiedene (auch nicht-morphologische) Kontexte vertiefend untersucht werden. Dieses Vorgehen ermöglicht folglich im Gegensatz zu den beiden oben angeführten Methoden zur Erhebung primärer Daten eine gewisse Flexibilität, die unter Berücksichtigung des geringen Vorwissensstandes äußerst günstig erscheint.

Die im Korpus analysierten Kasusformen versprechen außerdem, deutlich weniger von standardsprachlichen Formen beeinflusst zu sein als etwa in einem Paradigma abgefragte Nennformen. Dieser Vorteil zeigt sich insbesondere bei spontansprachlichen Korpusdaten. Zudem ermöglichen Korpusdaten die frequenzbasierte Analyse von Kasusformen und Mustern der Kasusmarkierung. Je nach Anlage des Korpus liegen mehrere Kasusformen, die einer paradigmatischen Zelle entsprechen würden, aus dem System einer Gewährsperson zur Analyse vor. So können zum einen gebrauchsbasierte Aussagen zur Frequenz bestimmter Kasusformen und damit zum Stellenwert bestimmter Wortarten und grammatischer Kategorien innerhalb des Kasusdiasystems getroffen werden. Zum anderen können frequenzbasiert prototypische und weniger prototypische Muster der Kasusmarkierung ermittelt werden.

Ein Problem der Korpusanalyse vollständiger Kasussysteme liegt in der begrenzten Datenmenge, die in einem Korpus naturgemäß vorhanden ist. Unter Umständen steht keine ausreichende Datenmenge zur Verfügung, um Kasusformen für jede paradigmatische Zelle in jeder grammatischen Kategorie und bei allen kasusmarkierenden Wortarten zu rekonstruieren. Als Beispiel können hier etwa die starken Adjektive genannt werden. Diese sind in gesprochener Sprache deutlich seltener als etwa definite Artikel und Pronomen, ${ }^{21}$ sodass unter Umständen je nach Korpusgröße keine vollständige paradigmatische Reihe rekonstruiert werden kann.

Auch die Frequenz der einzelnen Wortarten und grammatischen Kategorien kann hier variieren, was beispielsweise bei einem übergreifenden Vergleich bestimmter Muster zu berücksichtigen ist. So lässt sich etwa die Frequenz des vollständig distinkten Musters beim Pronomen mit der beim Adjektiv nicht über die absoluten Zahlen vergleichen, da, wie oben erwähnt, das Adjektiv allgemein deutlich seltener in gesprochener Sprache belegt ist als das Pronomen.

Zudem stellt die dialektgeographische Analyse auf Basis von Korpusdaten methodisch ein äußerst umfangreiches Unterfangen dar. Die Daten müssen zunächst einem geographischen Referenzpunkt zugeordnet und vollständig nach

21 Vgl. etwa Ruoff (1981: 20) zur Frequenz im gesprochenen Oberdeutschen: Adjektive: 2,8\%, Artikel, Fragewort, Pronomen (zusammen): 22,49\%. 
möglicherweise relevanten Belegen, d. h. nach allen im Diasystem angenommenen kasustragenden Wortarten, durchsucht und annotiert werden.

Perrig (2018) arbeitet mit den Dialektparabeln von Stalder (1981) - Übersetzungen eines biblischen Textes in je eine dialektale Variante für jeden Kanton in der Schweiz - und damit mit einem eher schriftsprachlichen Parallelkorpus. Sie problematisiert dabei insbesondere die eher undurchsichtige Datengrundlage: Verfasser der einzelnen Texte sowie deren mögliche Gewährspersonen und auch die Übersetzungsgrundlage sind unbekannt (vgl. Perrig 2018: 87-91). Auch bezüglich der Analyse von Kasus gestaltet sich die Datengrundlage als weniger homogen, als ein auf Übersetzungen basierendes Parallelkorpus vermuten lassen würde: Trotz der einheitlichen Übersetzungsgrundlage unterscheidet sich die ohnehin geringe Anzahl der Belege für die von Perrig (2018) untersuchten Wortformen (in diesem Fall für maskuline Definitartikel) in den Übersetzungen. Auch die Belegzahl der beiden untersuchten Kasus variiert: Es finden sich mehr Belege für Nominativ-als für Akkusativformen (Perrig 2018: 90).

Meyer (1967: 13-14), der das Spontanmaterial des SDS (des Sprachatlas der Deutschen Schweiz) und damit ein gesprochensprachliches Korpus nutzt, bemängelt die große Einschränkung der Kontexte des sprachlichen Materials und das Fehlen größerer Redezusammenhänge - die Daten wurden im Rahmen der direkten Erhebungen zum SDS erhoben (vgl. Hotzenköcherle 1962a) und basieren auf Redeanteilen, die sich neben der Bearbeitung eines Fragebuchs ergeben haben. Das Spontanmaterial ließe aufgrund der restringierten Kontexte innerhalb der Abfragesituation lediglich zuverlässige Aussagen über Nominative und freie Akkusative zu. Auch für eine Analyse und Interpretation der Muster in Bezug auf syntaktische oder stilistische Kategorien sei die Datengrundlage ungeeignet (Meyer 1967: 13-14). Deutlich freiere Redeanteile und damit vielfältigere Belege verspricht Rowleys (1997) Material: Die Aufnahmen zum Deutschen Spracharchiv bieten natürliche, frei gesprochene Sprache in initiierten Erzählmonologen (vgl. Stift/Schmidt 2014: 365).

Als problematisch erweist sich in den Arbeiten von Meyer (1967) und Rowley (1997) allerdings die mangelnde Transparenz der Analyse selbst. So geht Rowley (1997: 13-15) zwar ausführlich auf die genutzte Datengrundlage, nicht aber auf die exakte Methode der Datenanalyse und -annotation ein. Er erwähnt lediglich eine vorbereitende "verschriftsprachlichte Wort-für-Wort-Übertragung“ (Rowley 1997: 14) auf Basis derer relevante Flexionsformen in phonetischer Umschrift exzerpiert wurden (Rowley 1997: 14). Dies lässt zwar auf eine vollständige und damit möglicherweise frequenzbasierte Analyse schließen, größere Transparenz bezüglich des paradigmatischen Bezugssystems oder der Operationalisierung von synkretischen und distinkten Formen innerhalb einer Korpusanalyse ist hier nicht gegeben. Trotzdem lassen die Arbeiten von Meyer 
(1967) und Rowley (1997) darauf schließen, dass eine korpusbasierte Analyse dialektaler Kasussysteme, auch in Bezug auf die geographische Gliederung des oberdeutschen Raums, wertvolle Erkenntnisse liefern kann.

Der Überblick hat gezeigt, dass die meisten der bisherigen Arbeiten eine Kombination verschiedener Methoden zur Analyse der geographischen Gliederung und der Struktur oberdeutscher Kasussysteme genutzt haben. Eine solche Methodenkombination wird auch in dieser Arbeit genutzt: Die Analyse von Grammatiken hat bislang einen großen Stellenwert in der kasusmorphologischen Forschung eingenommen. Daher wird sich Abschnitt 2.3.5 einer präzisierenden Neuauswertung dieser Daten annehmen. Diese verspricht einen relativ feinmaschigen und dennoch geographisch breiten Überblick über bestimmte Muster der Kasusmarkierung. Da eine tonaufnahmenbasierte Korpusanalyse sowohl den Vorteil relativ natürlicher Sprache als auch einen tieferen Einblick in Interaktionen und Quantitäten im Kasusdiasystem verspricht, wird diese den empirischen Kern dieser Arbeit bilden und sowohl die Grundlage der strukturellen als auch der geographischen Untersuchung darstellen.

\subsubsection{Kartierung und Darstellung von Mustern der Kasusmarkierung}

Das folgende Kapitel widmet sich der Form der Ergebnispräsentation und Darstellungsmethode verschiedener Muster der Kasusmarkierung im Raum, die die bisherigen Arbeiten genutzt haben. Die kartographische Abbildung räumlicher Strukturen wird dort zumeist durch eine zusätzliche Beschreibung ergänzt. Dieses Vorgehen bietet sich zur Darstellung einer komplexen Kategorie wie Kasus durchaus an. Es können auf diese Weise allgemeine Tendenzen und Gemeinsamkeiten und damit die konstituierenden Faktoren des Kasusdiasystems beschrieben werden. Zudem können komplexe Einzelphänomene und deren Ursachen wie etwa die Interaktion mit nicht-morphologischen Faktoren auf diese Weise ausführlicher dargestellt werden. Ruoff (1973: 63) ist sogar der Meinung, dass sich morphosyntaktische Eigenschaften - auf Kasus als morphologisches System nimmt er keinen direkten Bezug - aufgrund eben solch komplexer Phänomene nicht zureichend in kartographischer Form abbilden lassen würden und argumentiert damit für eine rein textgestützte Darstellung (vgl. Ruoff 1973: 63). Kartographische Darstellungen tragen jedoch erheblich zur Übersichtlichkeit und Vergleichbarkeit dialektgeographischer Ergebnispräsentationen bei. Eine beziehungsweise mehrere Karten bieten einen einfachen Zugang und schnellen Überblick über die räumliche Gliederung kasusmorphologischer Muster und damit über die Verbreitung bestimmter Teilsysteme. Sie sind daher zur grundlegenden Orientierung unverzichtbar. 
Meyer (1967), Seiler (2003), Rabanus (2008), Rowley (1997) und Perrig (2018) nutzen Kartierungen als Ergänzung zu ausführlicheren Systembeschreibungen. Neben kurzen Beschreibungen, die sich primär auf das Diasystem beziehen, stellt Shrier (1965) die kartographischen Darstellungen ins Zentrum ihrer Ergebnispräsentation. Die oben beispielhaft mit Ruoff (1973) angeführte Kritik der mangelhaften Komplexität bei der Darstellung mithilfe von Karten soll dabei keineswegs von der Hand gewiesen werden. Es versteht sich von selbst, dass nicht alle geographischen Differenzen gesamter Teilsysteme in einer Karte abgebildet werden können. Vielmehr werden je nach Erkenntnissinteresse Muster aus verschieden großen Ausschnitten von Teilsystemen bzw. von Bündeln grammatischer Kategorien kartiert und damit diejenigen Faktoren herausgearbeitet, die im untersuchten Diasystem raumbildend sind.

Während Meyer (1967) teilweise relevante syntaktische Kontexte in seinen Karten andeutet, ${ }^{22}$ nutzt Shrier (1965) einzelne Karten, die ausschließlich durch morphologische Kategorien determinierte Ausschnitte zeigen. Zur geographischen Illustration ihrer Ergebnisse erstellt Shrier (1965) acht Teilkarten zu Mustern der Kasusmarkierung, die sich jeweils auf einzelne Wortarten in bestimmten Genera beziehen (z. B. auf den maskulinen Definitartikel). Hierbei wird das jeweilige Muster für jeden Ortspunkt einer Grammatik durch ein eigenes Punktsymbol in der Karte dargestellt. Abbildung 4 illustriert beispielhaft die Teilkarte zu den Mustern beim maskulinen Definitartikel.

In der Legende, die sich ausformuliert am unteren Ende befindet, nutzt Shrier (1965) eine Notation, bei der ein Schrägstrich eine Distinktion kennzeichnet: NA/D zeigt damit beispielsweise ein Muster mit distinktem Dativ und Synkretismus von Nominativ- und Akkusativ; N/AD einen Synkretismus von Akkusativ und Dativ bei distinktem Nominativ und NAD einen totalen Synkretismus. Diese Notation zur Beschreibung der verschiedenen Muster wird im Folgenden auch in dieser Arbeit genutzt. Neben den Teilkarten erstellt Shrier (1965) zudem Kombinationskarten. Dort werden die Muster in größeren Systemausschnitten beziehungsweise Kategorienbündeln dargestellt. Es werden beispielsweise die Muster der maskulinen Wortarten (Karte 10), die Tendenz zum Nominativ-AkkusativSynkretismus im Maskulinum (Karte 12) sowie alle Kategorien, in denen vollständige Kasusdistinktion innerhalb der Teilsysteme auftritt (Karte 13) in je einer Kombinationskarte gebündelt. Abbildung 5 zeigt zwei Typen von Kombinationskarten. Die erste bildet Areale mit unterschiedlichen Systemen durch Flächen mit

22 Vgl. dazu etwa Meyer (1967: Karte 5). Auf der Karte, die ansonsten lediglich einzelne Formen der morphophonologischen Oberflächenstruktur durch Punktsymbole abbildet, deutet eine Schraffur ein Gebiet an, in dem eine bestimmte Form obligatorisch nach Präpositionen auftritt. 


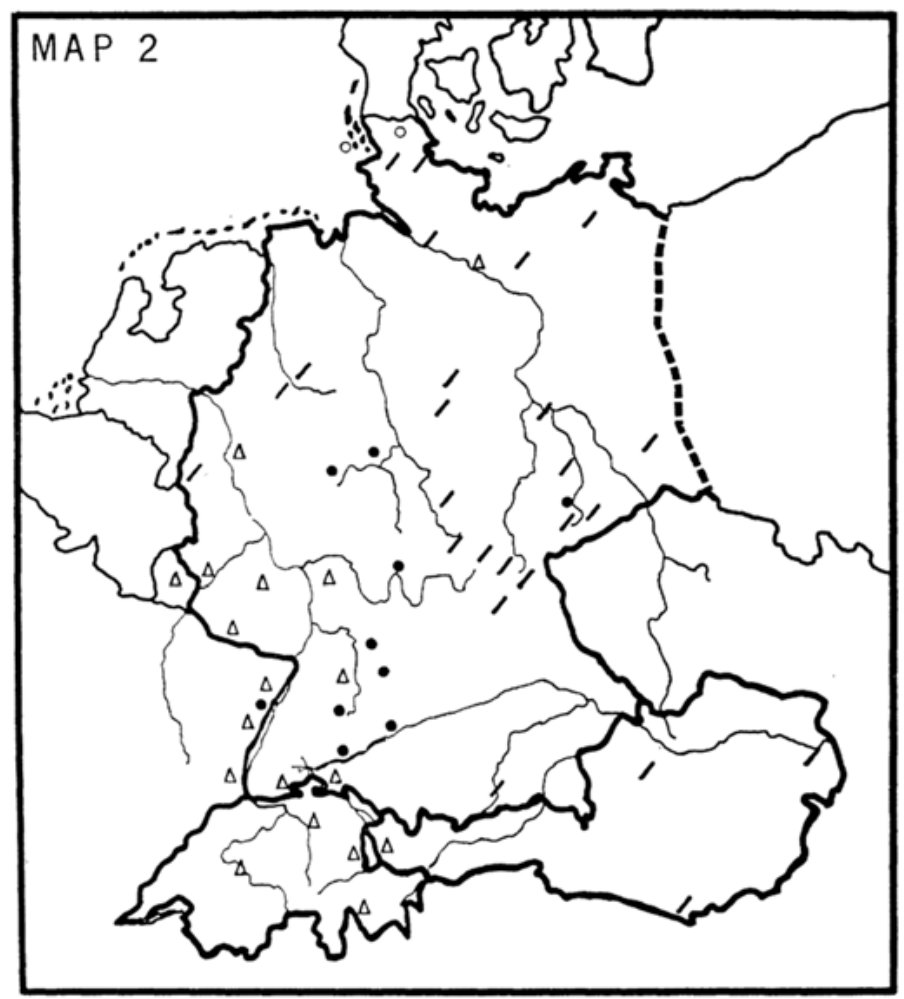

Map 2. Masculine definite article

Open circles, NAD case system; short diagonal lines, N/AD case system; triangles, NA/D case system; black circles, N/A/D case system.

Abb. 4: Teilkarte zu Mustern der Kasusmarkierung beim maskulinen Definitartikel aus (Shrier 1965: Karte 2).

verschiedenen Strukturen ab, die zweite Karte stützt sich auf Isoglossen zur Abgrenzung räumlicher Gliederung für unterschiedliche grammatische Kategorien.

Shriers (1965) Arbeit ist, wie oben dargestellt, äußerst gut für einen ersten, groben Überblick über die geographische Gliederung dialektaler Kasussysteme geeignet. Als Arbeitsgrundlage für aufbauende Studien zu kasusmorphologischen Phänomenen, als die sie häufig genutzt wird, erweist sie sich allerdings als äußerst problematisch. Insbesondere Shriers (1965) Methodik der Kartierung, aber auch die Darstellungsweise zeigen hier einige Probleme:

Während die grundlegende Methode der Punktsymbolmarkierung und insbesondere die Kartierung von Mustern der Kasusmarkierung durchaus zielführend sind, ist die graphische Darstellung der Ergebnisse als relativ proble- 

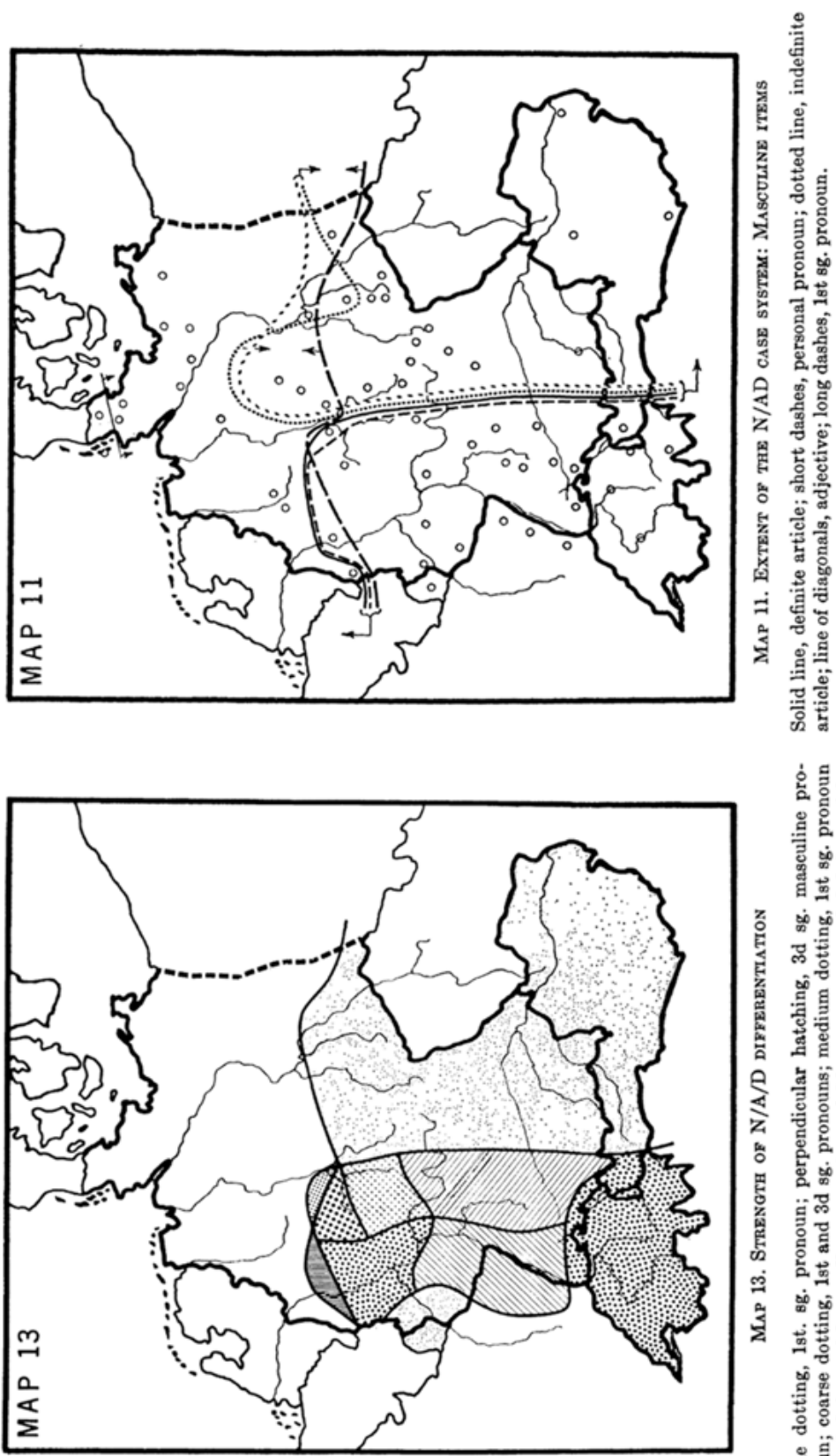

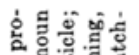

은

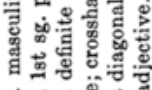

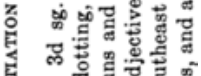

航

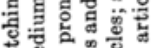

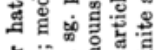

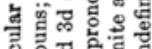

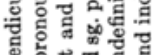

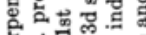

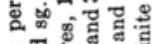

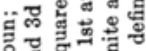

诘

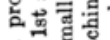

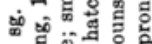

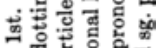

ô

要要要

.

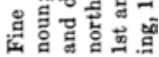

Abb. 5: Kombinationskarten zu raumbildenden Faktoren: Ausprägung der vollen Distinktion und Muster in maskulinen Kategorien (Shrier 1965: Karten 11 und 13). 
matisch zu bezeichnen (vgl. nochmals Abb. 4). Bedingt durch die technischen Möglichkeiten zur Entstehungszeit der Arbeit sind die Karten recht unübersichtlich gestaltet und aus heutiger Perspektive schlichtweg nicht mehr zeitgemäß. Neben dem Fehlen geographischer Referenzen (außer den äußeren politischen Grenzen und einigen Flüssen ist keine geographische Referenz angegeben $)^{23}$ ist insbesondere die ausformulierte Legende $\mathrm{zu}$ nennen, die durch die bloße Beschreibung der schwarz-weiß gehaltenen Symbole kein schnelles Erfassen der abgebildeten Muster ermöglicht.

Ebenso weisen die Karten einige inhaltliche Fehler auf: So widersprechen sich etwa Karten 2 und 13 (vgl. Shrier 1965: 432-434) für das in dieser Arbeit relevante Untersuchungsgebiet in Baden-Württemberg und Bairisch-Schwaben. Während Karte 2 distinkte Muster für den Bereich des westlichen Zentraloberdeutschen beim maskulinen Definitartikels abbildet, findet sich dieser nicht in Karte 13 zur allgemeinen Übersicht über distinkte Muster verschiedener Wortarten im besagten Gebiet (vgl. dazu näher 2.3.4). Es lässt sich annehmen, dass der Bereich dort in der Legende mit dem benachbarten Gebiet auf der Karte, wo der maskuline Definitartikel das Muster NA/D zeigt, vertauscht worden ist. Zudem wird in der Legende von Karte 13 ein N/A/D-Muster für das Personalpronomen angeführt, ohne Genus und Numerus näher zu spezifizieren. Da, wie in 2.2.2.1 jedoch eingehend erläutert, im Plural und im Femininum und Neutrum Singular eine gewisse Kasusnivellierung stattgefunden hat, kann sich die Legende jedoch ausschließlich auf das Maskulinum beziehen, was hier nicht transparent gemacht wurde (vgl. auch Ellsäßer 2020: 63).

Das größte Problem, das die Arbeit von Shrier (1965) als Grundlage für heutige Arbeiten bietet, liegt in der fehlenden geographischen Referenzierung der genutzten Ortsgrammatiken. Diese werden zwar durch Nummern auf Karte 1 (Shrier 1965: 422) illustriert; ein Schlüssel über die genutzten Ortsgrammatiken oder gar die Ortspunkte, auf die sich diese beziehen, liegt der Arbeit allerdings nicht bei. ${ }^{24}$ Die Ergebnisse können daher nicht direkt auf die anderer Arbeiten bezogen oder geographisch exakt verortet werden.

23 In König et al. (2015), wo eine Auswahl von Shriers (1965) Karten repliziert wurde, wurden diese um grundlegende geographische Referenzen ergänzt und sind somit etwas übersichtlicher als im Original.

24 Ein besonderer Dank gilt an dieser Stelle Martha Birnbaum (vormals Shrier) für Ihre Hilfsbereitschaft und die vertiefenden Auskünfte zu ihrer Methodik und Datengrundlage, die sich zwar nicht vollständig rekonstruieren lässt, deren Umfang nun allerdings einzugrenzen ist: Die in Shrier (1965) genutzten Orts- und Dialektgrammatiken entstammen allesamt dem Bestand der Columbia University Libraries, der auch online einsehbar ist. Ein Verzeichnis der konkret genutzten Werke existiert nicht. 
Zudem weist die Analyse ein relativ grobmaschiges Ortsnetz auf. Mit lediglich 55 Ortspunkten ist das gesamte deutschsprachige Gebiet kaum vollständig repräsentiert; insbesondere im gesamten bairischen Gebiet finden sich große Lücken. Daher erstaunt es umso mehr, dass Shrier (1965) zur Kartierung der allgemeinen Tendenzen der einzelnen Teilsysteme Isoglossen- beziehungsweise Isoglossenkombinationskarten angelehnt an die traditionelle phonologischen Dialektgliederung erstellt. ${ }^{25}$ Auf Basis der geringen Ortsdichte in Shrier (1965) kann nicht eindeutig festgestellt werden, ob (kasus-)morphologische Phänomene derart eindeutig abzutrennende Areale bilden. Es wäre durchaus möglich, dass sie vielmehr kontinuierliche geographische Übergangsstrukturen zeigen, wie sie beispielsweise in der Tradition der Dialektsyntax angesetzt werden (vgl. dazu näher 4.3). Rowleys (2004) punktuelle Verdichtung der Karten von Shrier (1965) auf Basis von Atlasdaten führt zu einer partiellen Korrektur des geographischen Verlaufs von Isoglossen, nicht aber zu einer Diskussion der Isoglossenstruktur an sich. Auch in den wenigen explizit morphologischen Karten in Rowley (1997: 240) werden Grenzen durch Isoglossen abgebildet. Dabei werden zum Teil Übergangsgebiete angesetzt, auf deren Struktur wird allerdings nicht weiter eingegangen. Rabanus (2008) hingegen kombiniert zum einen Punktsymbolkartierung mit einzelnen Isoglossen (vgl. etwa Rabanus 2008: 227), nutzt aber, ebenso wie Seiler (2003) und Perrig (2018), zum anderen auch reine Punktsymbolkarten - die Form der Kartierung, die auch in den Teilkarten in Shrier (1965) gebraucht wird. In Seiler (2003: 269) findet sich zudem noch eine Kartierungsform, bei der kleinräumige Gebiete entsprechend der dort gefundenen Phänomene schraffiert sind. Ebenso wie Punktsymbole haben auch diese kleinräumigen Schraffuren den Vorteil, dass, insbesondere bei einem eher groben Ortsnetz, weniger Verallgemeinerungen und Interpretationen der Daten für die Kartierung nötig sind als bei einer Kartierung mit festen Isoglossen. Zudem können diese Darstellungsformen auch möglicherweise „weiche“ Übergänge, wie etwa ein Kontinuum, sichtbar machen.

Die Übersicht zur Darstellung dialektaler Kasusdiasysteme hat gezeigt, dass diese nicht vollständig kartographisch darzustellen sind. Es lohnt sich vielmehr, einzelne Systemausschnitte, die im jeweiligen Gebiet raumbildend sind, in Karten abzubilden. Teilkarten können dabei die Grundlage für darauf aufbauende Systemkarten bilden. Die Probleme der Karten in Shrier (1965) zeigen, wie relevant die Transparenz der Datengrundlage und die Übersichtlichkeit der Darstellung für die Kartierung verschiedener Muster der Kasusmarkie-

25 Vergleiche zu den verschiedenen Formen der Kartierung in der primär phonologisch interessierten Dialektgeographie beispielsweise Mathussek (2014: 40-70). 
rung sind. Bestimmte Einflüsse, wie etwa die Interaktion des Kasusdiasystems mit nicht-morphologischen Faktoren, scheinen sich allerdings nur schwer vollständig in eine kartographische Übersicht integrieren zu lassen - einzelne Ausnahmen wie Meyer (1967) sind dabei jedoch zu erwähnen. Einzelphänomene können also durchaus in einer Teilkarte abgebildet, jedoch nicht übersichtlich im Gesamtkontext kartographisch dargestellt werden.

\subsubsection{Geographie der Kasusmorphologie: Literaturbasierte Erkenntnisse}

Das folgende Kapitel skizziert nun konstituierende und raumbildende Faktoren des Kasusdiasystems im hier untersuchten Gebiet (s. Abb. 1), die sich aus der Forschungsliteratur ergeben. Grundlegend lassen sich die folgenden Annahmen treffen: Bis auf wenige Gebiete im Höchstalemannischen und einige relikthafte Konstruktionen ist der synthetische Genitiv aus den deutschen Dialekten nahezu vollständig verschwunden. Diese Relikte umfassen z. B. temporale adverbiale Ausdrücken (z. B. abends), formelhafte Wendungen (z. B. um Gottes Willen, Mutter Gottes, des Lebens froh sein) sowie Personennamen (z. B. s'Grubers Hans, Sylvias Bruder) ${ }^{26}$ (vgl. etwa Mironow 1957: 393, Schirmunski 1962: 433-437). Die relikthaften Formen reichen jedoch nicht aus, um den synthetischen Genitiv als voll funktionsfähigen Kasus im untersuchten Diasystem anzusetzen.

Im hochdeutschen Gebiet werden daher gemeinhin drei abstrakte Kasus angenommen: Nominativ, Akkusativ und Dativ (vgl. etwa Shrier 1965: 421 oder Dal 1971b: 173). Dabei zeigen Feminina und Neutra im Singular im gesamten oberdeutschen Gebiet ein einheitliches Muster von NA/D (vgl. Shrier 1965: Karten 6-8 und Rabanus 2008: 151-153). Dieses Muster beschreibt Rabanus (2008: 151-153) außerdem für den Plural der Personalpronomen der 3. Person im südlichen Baden-Württemberg und Bayerisch-Schwaben. Zudem nimmt er dort ein N/AD-Muster für den Plural des Personalpronomens der 1. und 2. Person an. ${ }^{27}$ Eine geographische Differenzierung der einzelnen Teilsysteme lässt sich lediglich auf Basis der Muster in der 3. Person Maskulinum Singular vermuten, der Kategorie, auf der auch die Kombinationskarten in Shrier (1965) beruhen. Neben den maskulinen Relationen führt Shrier (1965: 434) auch das

26 Das Phänomen der relikthaften Genitivflexion an Personennamen in deutschen Dialekten wird etwa in Nübling/Schmuck (2010) und Dammel/Berchtold (2014) angesprochen.

27 Rabanus (2008: 189-196) beschreibt in Bayerisch-Schwaben zudem weitere Nivellierungstendenzen beim Personalpronomen der 1. und 2. Person Plural. Diese setzt er jedoch für ein Gebiet an, das sich nicht mit dem hier untersuchten Gebiet überschneidet und daher nicht in diese Übersicht eingeht. 
Personalpronomen der 1. Person Singular zur geographischen Gliederung an, für das sie jedoch im gesamten hochdeutschen Gebiet das Muster der vollen Distinktion ansetzt.

Abbildung 6 und 7 zeigen jeweils eine unter Berücksichtigung der problematischen Karten bestmögliche Projektion eben dieser raumbildenden Faktoren aus Shrier (1965) auf das hier untersuchte Gebiet des Oberdeutschen in

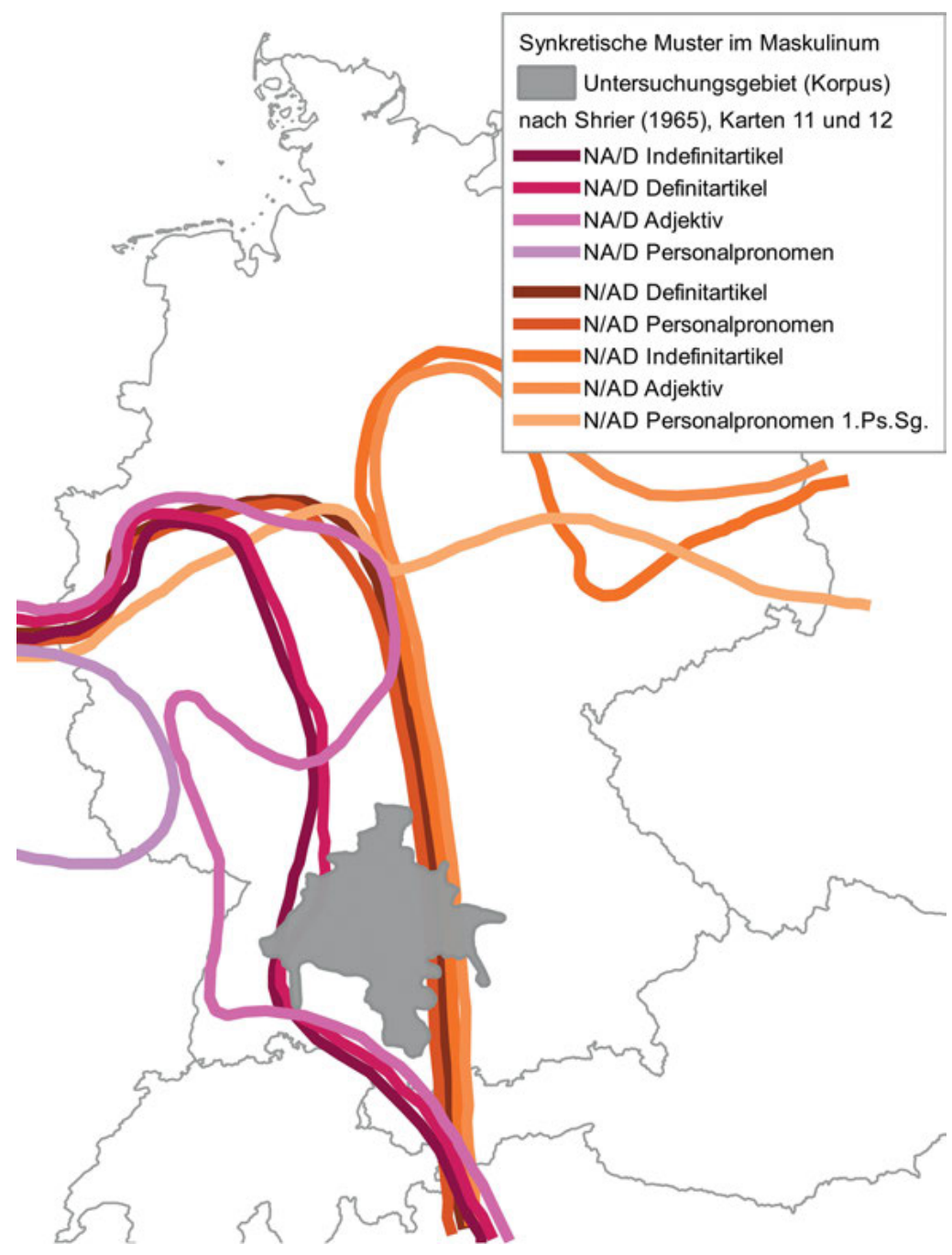

Abb. 6: Eigene Darstellung der Karten zu synkretischen Mustern im Maskulinum nach Shrier (1965: Karten 11 und 12). 


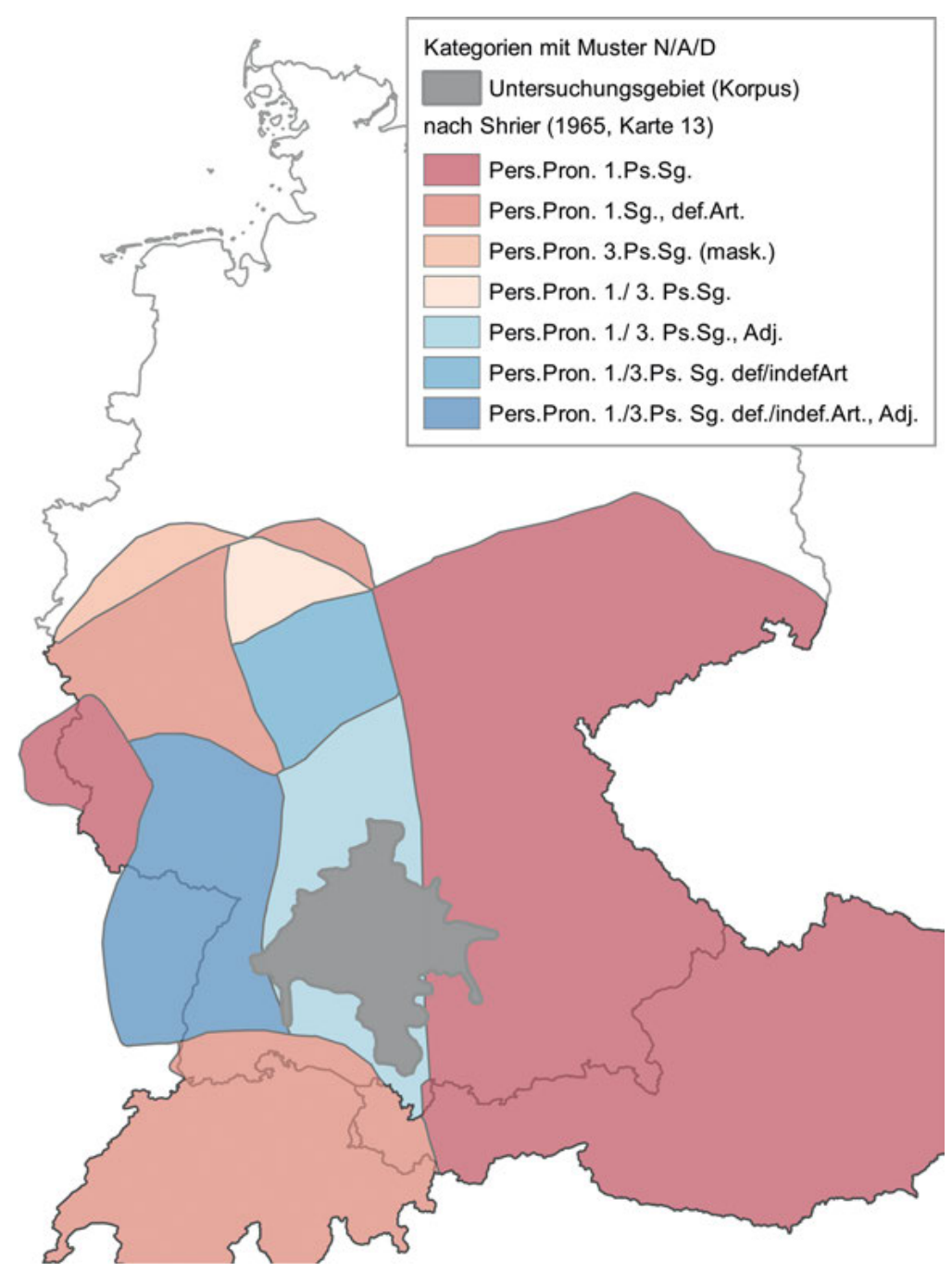

Abb. 7: Eigene Darstellung der Karte zu Kategorien mit Muster N/A/D nach Shrier (1965: Karte 13).

Baden-Württemberg und Bairisch-Schwaben. In Abb. 6 werden dabei die Karten zu synkretischen Mustern im Maskulinum, die Shriers (1965) Raumgliederung in dieser Kategorie ausmachen, kombiniert. Der Untersuchungsraum der Korpusanalyse ist durch ein hellgraues Polygon gekennzeichnet.

Shrier (1965) setzt im hochdeutschen Raum ein Isoglossenbündel an, das etwa entlang der politischen Grenze von Baden-Württemberg und Bayern verläuft 
(und von dort weiter in den Norden reicht) (Shrier 1965: 434) und zwei größere Räume voneinander trennt: Östlich dieses Isoglossenbündels zeigt sie für maskuline Wortarten - den maskulinen Definit- und Indefinitartikel, das Adjektiv und das Personalpronomen im Maskulinum - eine Tendenz zum synkretischen Dativ auf (N/AD). Die einzelnen, hier in ihrer Farbintensität abgestuften Isoglossen bezeichnen dabei die Gebietsgrenzen der einzelnen Wortarten mit diesem Muster, d. h. des maskulinen definiten und indefiniten Artikels, des Adjektivs und des Personalpronomens, wobei die Westgrenzen des N/AD-Musters jeweils in Grüntönen verzeichnet sind. Ausgehend von der Projektion in Abb. 6 lässt sich annehmen, dass das gesamte Isoglossenbündel das Untersuchungsgebiet der Korpusanalyse im östlichen Bereich schneidet und sich dort, wie im gesamten östlichen Oberdeutschen, in allen maskulinen Relationen das Muster N/AD, d. h. ein Synkretismus von Dativ und Akkusativ bei distinktem Nominativ findet. Rowley (2004: 347) bezeichnet dieses Muster bezugnehmend auf Artikel als „maskulinen Sonderweg“, womit er auf den Umstand abzielt, dass das synkretische Muster des Maskulinums hier vom Muster NA/D in den anderen Genera abweicht. Wie oben bereits angeführt, erwähnt auch Dal (1971a: 188) dieses Muster im Maskulinum, interpretiert es aber als rein phonologisch determiniertes System, dass keine morphologische Systemrelevanz besitzt.

Das Gebiet westlich des Isoglossenbündels lässt sich in zwei Bereiche unterteilen, die sich beide durch eine distinkte Dativform vom östlichen Gebiet unterscheiden: Im äußersten Westen wird ein Gebiet mit einer Tendenz zum Muster NA/D angesetzt. Beim Definitartikel wird dieses Muster nach Hildebrand (1869) als „rheinischer Akkusativ“28 bezeichnet. Abbildung 6 verzeichnet in Pinktönen die Ostgrenzen des Gebietes, die dieses Muster bei den verschiedenen maskulinen Wortarten zeigt. Das Untersuchungsgebiet wird im Westen von den entsprechenden Isoglossen des Definit- und Indefinitartikels geschnitten. In diesen Wortarten lassen sich demnach Belege des Musters NA/D im Maskulinum im Gebiet vermuten. Rowley (2004: 357) korrigiert einzelne Isoglossen, auch die des Definitartikels, aufgrund seines Materials aus Atlasdaten noch etwas weiter in den Osten und setzt das Muster NA/D damit für einen deutlich größeren Bereich innerhalb des Untersuchungsgebiets dieser Arbeit an. ${ }^{29}$

28 Hildebrand (1869: 447) unterscheidet bei dem mit Shrier (1965) als NA/D bezeichneten Muster zwischen einem System, das eine historische Nominativform zum Ausdruck des abstrakten Akkusativs benutzt - den eigentlichen „rheinischen Akkusativ“ - und einem System, in dem eine historische Akkusativform den abstrakten Nominativ ausdrückt. Beide Systeme zeigen wiederum unterschiedliche geographische Verbreitung.

29 Inwiefern dies tatsächlich, wie in Rowley (2004: 346) argumentiert, eine diachrone Expansion des Musters darstellt, ist auf Basis der geringen Datengrundlage und schlechten geographischen 
Im Zentrum des hochdeutschen Gebiets und damit auch im Großteil des Untersuchungsgebietes sind keine synkretischen Muster im Maskulinum verzeichnet. Hier wird die volle Distinktion von Nominativ, Akkusativ und Dativ (N/A/D) für diese Kategorie angenommen. Genaueren Aufschluss darüber verspricht Abb. 7, die auf Basis einer Georeferenzierung von Karte 13 aus Shrier (1965) generiert wurde. Diese Karte führt für die einzelnen Gebiete auf, in welchen Kategorien die dort angenommenen Teilsysteme volle Distinktion der drei Kasus zeigen.

Dieses Muster wird bei Personalpronomen, insbesondere der 1. Person Singular, ${ }^{30}$ im Allgemeinen länger erhalten als bei anderen Wortarten. ${ }^{31} \mathrm{Im}$ östlichen Bereich findet sich nach Shrier (1965: Karte 13) die Distinktion aller drei abstrakten Kasus ausschließlich beim Personalpronomen der 1. Person Singular. Die übrigen Wortarten weisen hier an mindestens einer Position in der paradigmatischen Reihe Synkretismus auf.

Das westliche Areal zeigt eine heterogenere Gliederung dieses distinkten Musters. Dabei weist ein zentraler Bereich direkt an der Grenze zum östlichen Areal Kasusdistinktion bei den meisten Wortarten auf. Diese Aussage treffe ich auf Basis der Annahme, dass es sich bei der bereits oben aufgeführten Unregelmäßigkeit in Karte 13 um einen Fehler der Kartierung in Shrier (1965) handelt, wobei dann in Abb. 7 das westliche - hier dunkelblaue - Areal mit dem östlichen - hier hellblauen - Areal zu tauschen wäre. Die Bereiche im Westen und Nordwesten des Hochdeutschen, d.h. in peripheren Gebieten, zeigen dann dieses Muster bei weniger Wortarten. So beschreibt auch Shrier (1965) das an der Grenze liegende Zentrum der Distinktion als kasusmorphologisch besonders konservativ, während die peripheren Regionen dynamischer seien und damit in mehr grammatischen Kategorien Synkretismus zeigen (Shrier 1965: 434-435).

Referenzierbarkeit der Karten in Shrier (1965) und der unterschiedlichen Datengrundlage der beiden Arbeiten schwer zu beurteilen. Hier ist nicht auszuschließen, dass die Daten bei Rowley (2004) schlichtweg dieselben Ergebnisse zeigen, die Karten von Shrier (1965) allerdings geographische Ungenauigkeiten aufweisen.

30 Shrier (1965) untersucht ausschließlich das Personalpronomen der 1. und 3. Person Singular, weswegen hier keine Aussagen über das der 2. Person oder Pluralkontexte getroffen werden können.

31 Dies kann zum einen darin begründet liegen, dass es sich um eine hochfrequente Wortart handelt, die Flexionskategorien durch Suppletion markiert, zum anderen auch daran, dass sie Portmanteumorpheme darstellen, die neben Kasus auch weitere Merkmale ausdrücken und daher ein gewisses Merkmalsspektrum auch beim Verlust eines einzelnen Merkmals erhalten bleibt. Ein Grund für den Erhalt der Distinktion lässt sich also im Typus der Kasusmarkierung finden - ein Aspekt, der in 4.2.2 näher ausgeführt wird. 
Auf Grundlage der Forschungsliteratur ergeben sich folglich mehrere Annahmen zur geographischen Gliederung des Kasusdiasystems, die es in der Arbeit zu überprüfen gilt: Erstens ist die hier angeführte raumgliedernde Kategorie - das Maskulinum Singular - zu verifizieren. Zweitens ist zu überprüfen, inwiefern sich die näherungsweise beschriebene Raumgliederung auf Grundlage der verschiedenen genutzten Datentypen und des dichteren Ortsnetzes bestätigen lassen. Und drittens ist die in 2.3.3 angeführte Frage zur geographischen Struktur der Gebietsgrenzen zu klären.

\subsubsection{Zwischenfazit}

Dieses Kapitel hat das Forschungsfeld der dialektgeographischen Kasusmorphologie in seinen Methoden und Vorgehensweisen umrissen und erste Annahmen zu relevanten Kategorien, Strukturen und Mustern der geographischen Gliederung des Untersuchungsgebiets getroffen. Anhand bisher zum hoch- beziehungsweise oberdeutschen Gebiet entstandener Arbeiten wurden zunächst die theoretische Fundierung und die Zugriffspunkte auf die Kategorie Kasus herausgearbeitet (2.3.1). Grundlegend richten sich diese Arbeiten zumeist an den Desideraten der strukturellen Dialektologie aus. Vergleiche zwischen Teilsystemen werden eher auf Grundlage von Mustern der Kasusmarkierung als auf Basis der morphophonologischen Oberfläche angestellt. Dieser Ansatz wird auch in der hier vorgestellten Analyse umgesetzt.

2.3.2 hat sich mit der Datengrundlage und der methodischen Ausrichtung der bisherigen Arbeiten zur Kategorie Kasus in den deutschen Dialekten beschäftigt und deren Vor- und Nachteile eingehend diskutiert. Eine Kombination verschiedener Daten und Methoden bei der dialektgeographischen Untersuchung hat sich hier als üblich und methodisch sinnvoll erwiesen und wird daher auch in dieser Arbeit umgesetzt: Eine Analyse von Ortsgrammatiken wird mit einer tonaufnahmenbasierten Korpusanalyse kombiniert.

Die Ergebnisdarstellung (2.3.3) gestaltet sich in allen Arbeiten grundsätzlich einheitlich: Karten werden hier mit vertiefenden systematischen Beschreibungen im Text kombiniert. Dabei zeigt insbesondere die Arbeit von Shrier (1965) ein relativ komplexes Kartierungssystem bestehend aus Teilkarten für einzelne grammatische Kategorien und Kombinationskarten, in denen jeweils mehrere Teilkarten kombiniert werden und damit ein Bild der allgemeinen Verbreitung eines bestimmten Systemausschnitts entsteht. Grenzen und Struktur der geographisch gegliederten Teilsysteme werden bislang primär anhand von Isoglossenkarten und vereinzelt auch durch Punktsymbolkarten abgebildet. Die Isoglossenkarten wurden hier aufgrund der geringen Datengrundlage kritisch hinterfragt. 
Da sich Shriers (1965) Arbeit als einzige direkt auf das Untersuchungsgebiet der Korpusanalyse beziehen lässt, bildete sie die Basis für die Beschreibung der literaturbasierten Erkenntnisse zur geographischen Gliederung im Untersuchungsgebiet und wurde lediglich für kleinere Teilgebiete durch Rabanus (2008) und Rowley (2004) ergänzt. Im Untersuchungsgebiet lassen sich drei verschiedene Teilsysteme erwarten, die sich auf Basis einer raumgliedernden Kategorie - den Mustern im Maskulinum - unterscheiden (2.3.4).

Übergreifend konnte in diesem Kapitel aufgezeigt werden, dass es sich bei der dialektgeographischen Kasusmorphologie um ein Feld handelt, das bislang zu wenig Aufmerksamkeit innerhalb der Forschung erfahren hat. Neben einer klaren Linie in der theoretischen Fundierung fehlen bislang insbesondere einheitliche, transparente und dem Gegenstand angemessene Konventionen und Anforderungen an Methodik und Datengrundlage. Die folgenden Kapitel werden daher einen Ansatz zur Analyse dialektaler Kasussysteme vorschlagen, der erstens auf Erkenntnissen der modernen morphologischen Theoriebildung fußt und zweitens maximale Transparenz bezüglich der Datengrundlage und des methodischen Vorgehens bietet. 
